\title{
A novel zerovalent manganese for removal of copper ions: synthesis, characterization and adsorption studies
}

\author{
A. O. Dada ${ }^{1}$ F. A. Adekola ${ }^{2}$ E. O. Odebunmi ${ }^{3}$
}

Received: 25 December 2014/ Accepted: 26 October 2015/Published online: 20 November 2015

(C) The Author(s) 2015. This article is published with open access at Springerlink.com

\begin{abstract}
Synthesis of nanoscale zerovalent manganese (nZVMn) by chemical reduction was carried out in a single pot system under inert environment. nZVMn was characterized using a combination of analytical techniques: Ultraviolet-Visible Spectroscopy, Fourier Transform Infrared Spectroscopy, Scanning Electron Microscopy, Transmission Electron Microscopy, Energy Dispersive X-ray, BET surface area and Point of Zero Charge. The adsorption physicochemical factors: $\mathrm{pH}$, contact time, adsorbent dose, agitation speed, initial copper ion concentration and temperature were optimized. The kinetic data fitted better to Pseudo second-order, Elovich, fractional power and intraparticle diffusion models and their validity was tested by three statistical models: sum of square error, Chi-square $\left(\chi^{2}\right)$ and normalized standard deviation $(\Delta q)$. Seven of the two-parameter isotherm models [Freundlich, Langmuir, Temkin, Dubinin-Kaganer-Raduskevich (DKR), Halsey, Harkin-Jura and Flory-Huggins] were used to analyse the equilibrium adsorption data. The Langmuir monolayer adsorption capacity $\left(Q_{\max }=181.818 \mathrm{mg} / \mathrm{g}\right)$ obtained is greater than other those of nano-adsorbents utilized in adsorption of copper ions. The equilibrium
\end{abstract}

A. O. Dada

dada.oluwasogo@1mu.edu.ng

$\triangle$ F. A. Adekola

fadekola@unilorin.edu.ng

1 Department of Physical Sciences, Industrial Chemistry, Landmark University, P.M.B.1001, Omu-Aran, Kwara, Nigeria

2 Department of Industrial Chemistry, University of Ilorin, P.M.B. 1515, Ilorin, Nigeria

3 Department of Chemistry, University of Ilorin, P.M.B. 1515, Ilorin, Nigeria adsorption data were better described by Langmuir, Freundlich, Temkin, DKR and Halsey isotherm models considering their coefficient of regression $\left(R^{2}>0.90\right)$. The values of the thermodynamic parameters: standard enthalpy change $\Delta H^{\circ}\left(+50.27848 \mathrm{~kJ} \mathrm{~mol}^{-1}\right)$, standard entropy change $\Delta S^{\circ}\left(203.5724 \mathrm{~J} \mathrm{~mol}^{-1} \mathrm{~K}^{-1}\right)$ and the Gibbs free energy change $\Delta G^{\circ}$ revealed that the adsorption process was feasible, spontaneous, and endothermic in nature. The performance of this novel nanoscale zerovalent manganese (nZVMn) suggested that it has a great potential for effective removal of copper ions from aqueous solution.

Keywords Manganese nanoparticles - Copper . Characterization · Kinetics · Isotherm · Thermodynamics
List of symbols
$C_{\mathrm{o}}$
Initial concentration of the $\mathrm{Cu}^{2+}$ solution $\left(\mathrm{mg} \mathrm{L}^{-1}\right)$
$C_{\mathrm{e}} \quad$ Equilibrium concentration of the $\mathrm{Cu}^{2+}$
$\left(\mathrm{mg} \mathrm{L}^{-1}\right)$
$W \quad$ Dry weight in gram of the nZVMn nano- adsorbent
$V \quad$ Volume of the $\mathrm{Cu}^{2+}$ solution (L)
$Q_{\mathrm{e}} \quad$ Amount of $\mathrm{Cu}^{2+}$ adsorbed at equilibrium per unit weight of nZVMn $\left(\mathrm{mg} \mathrm{g}^{-1}\right)$
$q_{t}$ Amount of $\mathrm{Cu}^{2+}$ adsorbed at any time (mg/ g)
$k_{1} \quad$ Pseudo first-order rate constant $\left(\mathrm{min}^{-1}\right)$
$k_{2} \quad$ Pseudo second-order adsorption rate
constant (g/mg min)
$h_{1} \quad$ Pseudo first-order initial adsorption rate (mg/g min)
$h_{2} \quad$ Pseudo second-order initial adsorption rate $\left(\mathrm{mg}^{2} / \mathrm{g}^{2} \mathrm{~min}\right)$ 
$\alpha \quad$ Constant in the Elovich rate equation (g $\mathrm{min}^{2} / \mathrm{mg}$ )

$\beta \quad$ Constant in the Elovich rate equation (g min/mg)

$k \quad$ Fractional power rate constant

$R \quad$ Gas constant $(\mathrm{J} / \mathrm{mol} \mathrm{K})$

$K_{\mathrm{F}} \quad$ Freundlich isotherm constant

$n_{\mathrm{F}} \quad$ Exponent in Freundlich isotherm

$Q_{\max } \quad$ Langmuir maximum monolayer coverage capacity of nZVMn $\left(\mathrm{mg} \mathrm{g}^{-1}\right)$

$K_{\mathrm{L}} \quad$ Langmuir isotherm constant $\left(\mathrm{L} \mathrm{mg}^{-1}\right)$

$R_{\mathrm{L}} \quad$ Dimensionless constant referred to as separation factor

$b_{T} \quad$ Temkin isotherm constant related to the heat of adsorption

$A_{T} \quad$ Temkin isotherm equilibrium binding constant $\left(\mathrm{Lg}^{-1}\right)$

$A_{\mathrm{DKR}} \quad$ DKR isotherm constant $\left(\mathrm{mol}^{2} / \mathrm{kJ}^{2}\right)$ related to free adsorption energy

$Q_{\mathrm{d}} \quad$ The theoretical isotherm saturation capacity (mg/g)

$\varepsilon \quad$ Polanyi potential $=R T \ln \left(1+1 / C_{\mathrm{e}}\right)$

$E \quad$ Mean adsorption free energy

$K_{\mathrm{H}}$ and $n_{\mathrm{H}} \quad$ Halsey constants

$A_{\mathrm{HJ}}$ and $B_{\mathrm{HJ}} \quad$ Harkin-Jura constants

$\theta$

$n_{\mathrm{FH}}$

$K_{\mathrm{FH}}$

$k_{\text {id }}$

$\mathrm{C}$

$R^{2}$

SSE

$\chi^{2}$

$\Delta q$

$\Delta H^{\circ}$

$\Delta S^{\circ}$

$\Delta G^{\circ}$

$T$

$K_{\mathrm{c}}$
Degree of surface coverage

Flory-Huggins' number of metal ions occupying adsorption sites

Flory-Huggin's equilibrium constant

Intraparticle diffusion rate constant $\left(\mathrm{mg} \mathrm{g}^{-1} \min ^{0.5}\right.$ )

Thickness of the boundary

Regression coefficient

Sum of square error

Chi-square test

Normalized standard deviation (\%)

Standard enthalpy change $\left(\mathrm{J} \mathrm{mol}^{-1}\right)$

Standard entropy change $\left(\mathrm{J} \mathrm{mol}^{-1} \mathrm{~K}^{-} 1\right)$

Standard Gibbs free energy $\left(\mathrm{J} \mathrm{mol}^{-1}\right)$

Absolute temperature (K)

Thermodynamic equilibrium constant

\section{Introduction}

Nanotechnology is the science of structuring matters into a large surface area which holistically possesses unique characteristics. This is part of modern science and its applications attract interest of researchers owing to the fact that it gives room for several innovations. The application of nanotechnology to waste water remediation vis-à-vis

heavy metal ions removal cannot be over emphasized (Dada et al. 2014a, b). The effectiveness of nanomaterials is majorly enhanced by its surface area (Jain et al. 2007; Prathna 2012). Copper is often released into the environment through anthropogenic activities. Soluble copper compounds post a number of threats to human health. Usually, water-soluble copper compounds occur in the environment through applications in agriculture. Copper toxicity affects human beings, aquatic organisms and plants (Roosta et al. 2014; Wojtysiak and Kudelski 2012). A number of adverse effects of copper exist due to overexposure ranging from irritation of the nose, mouth and eyes, headaches, stomachaches, dizziness, vomiting, hematemesis, diarrhoea, hypotension, melena, coma, jaundice to liver and kidney damage and even death (Bonnie et al. 2007; Brewer 2010). However, several methods such as precipitation, cementation, reverse osmosis, ion-exchange, electro-dialysis have been used to remove these heavy metals; yet, the problems still persist because of myriad of limitations of these methods (Prasad and Elumalai 2011). Adsorption has proven to be an efficient and cost-effective method of combating this problematic and toxic heavy metal ion. Some researchers have reported the use of some nano-adsorbents such as aminofunctionalized magnetic nanoparticles (Kumar and Yadav 2011), pectin-iron oxide magnetic nanocomposite (Xi et al. 2011) for the adsorption of copper(II) ions. Nevertheless, to the best our knowledge, there has been no report on preparation, characterization and adsorption studies of copper onto nanoscale zerovalent manganese (nZVMn). There are no data on detailed kinetic and isotherm models of adsorption of $\mathrm{Cu}$ (II) onto nanoscale manganese. Therefore, the objectives of this study are: to investigate the synthesis of nanoscale zerovalent manganese (nZVMn) in a single pot system using bottom-up approach via chemical reduction; carrying out the characterization of nZVMn and investigate its application in adsorption of $\mathrm{Cu}(\mathrm{II})$ ions. The effect of adsorbent dose, stirring speed, contact time, $\mathrm{pH}$, initial $\mathrm{Cu}$ (II) concentration and temperature was investigated. The kinetic data were tested with pseudo first-order, pseudo second-order, Elovich, Fractional Power (Power function), and intraparticle diffusion models to determine the rate of adsorption and mechanism of the process. The equilibrium data were also subjected to seven isotherm models: Langmuir, Freundlich, Temkin, Dubinin-Kaganer-Raduskevich (DKR), Halsey and Harkin-Jura and Flory-Huggins. The thermodynamic parameters such as enthalpy change $(\Delta H)$, entropy change $(\Delta S)$ and Gibb's free energy change $(\Delta G)$ were calculated. The post adsorption characterization of the adsorbent (nZVMn) was carried out using scanning electroscope (SEM) and energy dispersive X-ray (EDX). Finally, the effect of salinity on adsorption of $\mathrm{Cu}$ (II) onto nZVMn was determined. 


\section{Materials and methods}

\section{Materials and synthesis}

All the reagents used are of analytical grade. Deionized deoxygenated water (sparged with nitrogen gas) was used all through for this synthesis. Sodium borohydride (SigmaAldrich, USA) was used for the chemical reduction, other reagents used were: $\mathrm{MnCl}_{2} \cdot 4 \mathrm{H}_{2} \mathrm{O}$ (Xilong Chemical, China), Absolute Ethanol (BDH) and $\mathrm{HNO}_{3}$ (SigmaAldrich, USA).

Nanoscale zerovalent manganese was synthesized by chemical reduction method in a single pot system via bottom-up approach (Dada et al. 2014a, b; Boparai et al. 2010; Chen et al. 2011; Liu (2008); Edison and Sethuraman 2013). In a typical procedure for nanoscale zerovalent manganese synthesis, $0.023 \mathrm{M}$ of $\mathrm{MnCl}_{2} \cdot 4 \mathrm{H}_{2} \mathrm{O}$ was prepared and tagged solution $\mathrm{A}$ and $0.123 \mathrm{M} \mathrm{NaBH}_{4}$ was prepared and tagged solution $\mathrm{B}$. Manganese chloride was reduced to zerovalent manganese according to the reaction below:

$\mathrm{Mn}^{2+}+2 \mathrm{BH}_{4}^{-}+6 \mathrm{H}_{2} \mathrm{O} \rightarrow \mathrm{Mn}^{0}+2 \mathrm{~B}(\mathrm{OH})_{3}+7 \mathrm{H}_{2} \uparrow$

Under inert condition in a glove box, solution B was added in drops to solution $\mathrm{A}$ in a three-neck round-bottom flask and rapid formation of zerovalent manganese with faint brownish colour was observed with a large evolution of hydrogen gas. As soon as the borohydride solution was added to manganese chloride solution, a faint brownish nanoparticle (nZVMn) appeared and the mixture was further stirred for $3 \mathrm{~h}$. Excess of borohydride solution was needed for better formation of nZVMn. However, nanoscale zerovalent manganese (nZVMn) was allowed to age overnight. nZVMn was separated from the solution using vacuum filtration apparatus and a cellulose nitrate membrane filter (Millipore filter) of $0.45 \mu \mathrm{m}$. The nZVMn was further washed with absolute ethanol three times and dried in a Genlab oven at $50{ }^{\circ} \mathrm{C}$ overnight to obtain a deep brown colour of nZVMn.

\section{Characterization of $\mathrm{nZVMn}$}

The adsorption band arising from the surface plasmon resonance in the nZVMn was determined using a Beckmann Coulter DU 730 Life Science UV-VIS spectrophotometer.

The information on the molecular environment of nZVMn was obtained from the spectrum recorded using Shimadzu FTIR model IR 8400S.

The surface morphology and elemental composition were determined using scanning electron microscopy (SEM) integrated with energy dispersive X-ray (EDX) analyzer. SEM images and EDX spectra were obtained using a TESCAN Vega TS 5136LM typically at $20 \mathrm{kV}$ at a working distance of $20 \mathrm{~mm}$. Samples for SEM analysis were prepared by coating them in gold using a Balzers' Spluttering device.

The transmission electron microscopy (TEM) was carried out using A Zeiss Libra 120 transmission electron microscope at $80 \mathrm{kV}$ voltage. This was useful to determine the size and shape of the nanostructure.

The determination of surface area, pore size and volume was done using Brunauer-Emmett-Teller (BET) and Barrett, Joyner, Halenda $(\mathrm{BJH})$ methods.

The $\mathrm{pH}$ Point of Zero charge ( $\mathrm{pH}$ pzc) is the $\mathrm{pH}$ at which the nZVMn surface submerged in an electrolyte $\left(0.1 \mathrm{M} \mathrm{NaNO}_{3}\right)$ exhibits zero net charge. This was carried out using the procedure reported by Srivastava et al. 2005 . The $\mathrm{pH}$ was varied from 2 to 12 by adjustments with $0.1 \mathrm{M} \mathrm{HNO}_{3}$ or $0.1 \mathrm{M} \mathrm{NaOH}$.

\section{Adsorption experiment}

\section{Batch adsorption studies}

Batch adsorption experiment was done by contacting $100 \mathrm{mg}$ of the nZVMn in $60 \mathrm{~mL}$ of Teflon bottle with $50 \mathrm{~mL}$ of $\mathrm{Cu}^{2+}$ concentrations intermittently for $3 \mathrm{~h}$ at optimum operational conditions. The mixture was filtered and the filtrate was immediately analysed for $\mathrm{Cu}^{2+}$ ions concentrations using atomic adsorption spectrophotometer (AAS) model AA320 N. The determination of the residual concentration using AAS was done in triplicate and the mean value for each set of the experiments was calculated. Investigation of other operational parameters such as effects of $\mathrm{pH}$, contact time, adsorbent dose, temperature and ionic strength was carried out following a similar procedure (Adekola et al. 2012; Hao et al. 2010). Adsorption capacity and the removal efficiency were obtained using Eqs. 2 and 3, respectively (Hameed et al. 2008):

$Q_{\mathrm{e}}=\frac{\left(C_{\mathrm{o}}-C_{\mathrm{e}}\right) V}{W}$,

$\% \mathrm{RE}=\frac{C_{\mathrm{o}}-C_{\mathrm{e}}}{C_{\mathrm{o}}} \times 100$,

where $Q_{\mathrm{e}}$ is the equilibrium adsorption capacity per gram dry weight of nZVMn $\left(\mathrm{mg} \mathrm{g}^{-1}\right), V$ is the volume of the $\mathrm{Cu}^{2+}$ solution $(\mathrm{L}), C_{\mathrm{o}}$ is the initial concentration of the adsorbate solution before adsorption $\left(\mathrm{mg} \mathrm{L}^{-1}\right), C_{\mathrm{e}}$ is the equilibrium concentration of the $\mathrm{Cu}^{2+}$ after adsorption ( $\left.\mathrm{m} \mathrm{L}^{-1}\right), W$ is the dry weight in gram of the nZVMn nano-adsorbent. The adsorption kinetics was conducted at optimum operational parameters as stated at the bottom of 
the plot from 10 to $120 \mathrm{~min}$. The kinetic data were fitted to five kinetic and mechanism models: pseudo first-order, pseudo second-order, Elovich, Fractional Power (Power function), and intraparticle diffusion models.

Effect of initial concentration was investigated by varying initial concentrations from 10 to $200 \mathrm{ppm}$ at optimum conditions. The equilibrium data were fitted to seven isotherm models: Langmuir, Freundlich, Temkin, Dubinin-Kaganer-Raduskevich (DKR), Halsey, HarkinJura and Flory-Huggins.

\section{Theory}

\section{Adsorption kinetics and mechanism}

To investigate the reaction mechanism and determine the rate-controlling step of the adsorption of $\mathrm{Cu}^{2+}$ onto nZVMn, pseudo first-order, pseudo second-order, Elovich, fractional power and intraparticle diffusion rate equations have been used to model the kinetics of $\mathrm{Cu}^{2+}$ adsorption. The quantity of copper uptake at the agitation time, $q_{t}$, is given by the expression:

$q_{t}=\frac{\left(C_{\mathrm{o}}-C_{t}\right) V}{W}$,

$C_{\mathrm{o}}$ and $C_{t}$ are the liquid-phase concentrations of the $\mathrm{Cu}^{2+}$ solution adsorbate at time 0 and any time $t$ while $V$ and $W$ are the same as defined in Eqs. 2 and 3 above. The experimental data obtained from the optimization of the contact time were tested with kinetic models to study mechanisms of adsorption and the rate-determining step.

The pseudo first-order (Lagergren's rate equation)

Interaction in a solid-liquid system based on the sorption capacity of nZVMn is described by pseudo first order (Lagergren's rate equation). It is assumed that one copper ion is sorbed onto one adsorption site on the nanoscale zerovalent manganese (nZVMn) surface:

$n Z V M n+C u_{a q}^{2+} \stackrel{k_{1}}{\longrightarrow} n Z V M n C u_{\text {solid }}$ phase

The linear form of pseudo first-order equation is generally expressed as:

$\log \left(q_{\mathrm{e}}-q_{t}\right)=\log q_{\mathrm{e}}-\frac{k_{1} t}{2.303}$,

$h_{1}=k_{1} q_{\mathrm{e}}$,

where $q_{\mathrm{e}}$ is the quantity of $\mathrm{Cu}^{2+}$ adsorbed at equilibrium per unit weight of the adsorbent $(\mathrm{mg} / \mathrm{g}), q_{t}$ is the amount of $\mathrm{Cu}^{2+}$ adsorbed at any time $(\mathrm{mg} / \mathrm{g}), h_{1}$ is pseudo first-order initial adsorption rate and $k_{1}$ is the pseudo first-order rate constant $\left(\mathrm{min}^{-1}\right)$.
The plot of $\log \left(q_{e}-q_{t}\right)$ versus $t$ should give a linear relationship and $k_{1}$ and $q_{\mathrm{e}}$ can be determined from the slope and intercept of the expression in Eq. 5a, respectively (Ho and McKay 2003).

\section{The pseudo second-order rate equation}

The pseudo second-order rate expression has been applied for analysing chemisorption kinetics from liquid solutions (Ho 2004). It is also assumed that copper ion is sorbed onto two adsorption sites on the nZVMn surface according to the interaction between copper ion and nanoscale zerovalent manganese (nZVMn):

$2 \mathrm{nZVMn}+\mathrm{Cu}_{\mathrm{aq}}^{2+} \stackrel{k_{2}}{\longrightarrow}(\mathrm{nZVMn})_{2} \mathrm{Cu}_{\text {solid phase }}$.

The linear form of pseudo second-order rate expression given by the expression:

$\frac{t}{q_{t}}=\frac{1}{k_{2} q_{\mathrm{e}}^{2}}+\frac{1}{q_{\mathrm{e}}} t$.

When $t$ tends to $0, h_{2}$ is defined as:

$h_{2}=k_{2} q_{\mathrm{e}}^{2}$.

Substituting $h_{2}$ into above equation, it becomes:

$\frac{t}{q_{t}}=\frac{1}{h_{2}}+\frac{1}{q_{\mathrm{e}}} t$

where $h_{2}$ is the initial adsorption rate. If the second-order kinetic equation is applicable, the plot $\mathrm{t} / q_{t}$ against $t$ should give a linear relationship from which the constants $k_{2}, q_{\mathrm{e}}$ and $h_{2}$ were determined (Ahmad et al. 2014a).

\section{The Elovich model}

This is generally described as:

$\mathrm{d} q / \mathrm{d} t=\alpha \exp \left(-\beta q_{t}\right)$.

Applying the boundary conditions $\left(q_{t}=0\right.$ at $t=0$ and $q_{t}=q_{t}$ at $t=t$ ), the simplified form of the Elovich equation is expressed as:

$q_{t}=\frac{1}{\beta} \ln (\alpha \beta)+\frac{1}{\beta} \ln (t)$,

where $q_{t}$ is the amount of adsorbate per unit mass of sorbent at time $(t)$, and $\alpha$ and $\beta$ are the constants slope and intercept of the determined from the linear plot of $q_{t}$ versus $\ln (t)$; where $\alpha$ is the initial adsorption rate $(\mathrm{mg} / \mathrm{g}-\mathrm{min})$ and $\beta$ is the desorption constant $(\mathrm{g} / \mathrm{mg})$ during any one experiment. The slope and intercept are $1 / \beta$ and $1 / \beta \ln (\alpha \beta)$, respectively. The $1 / \beta$ value reflects the number of sites available for adsorption whereas the value of $1 / \beta \ln (\alpha \beta)$ indicates the adsorption quantity when $\ln (t)$ equals to zero (Ayanda et al. 2013; Ahmad et al. 2014b). 


\section{The fractional power}

The fractional power known as power function model can be expressed as:

$q_{t}=k t^{v}$.

The Eq. 11 above is linearized as:

$\log \left(q_{t}\right)=\log (k)+v \log (t)$

where $q_{t}$ is the amount of adsorbate per unit mass of sorbent, $k$ is a constant, $t$ is time, and $\mathrm{v}$ is a positive constant $(<1)$. The parameters $v$ and $k$ were determined from slope and intercept of a linear plot of $\log \left(q_{t}\right)$ versus $\log$ (t) (Ayanda et al. 2013).

\section{Intraparticle diffusivity}

The intraparticle diffusion equation is expressed as:

$q_{t}=k_{\mathrm{id}} t^{0.5}+C$,

where $k_{\mathrm{id}}$ is the intraparticle diffusion rate constant ( $\mathrm{mg} \mathrm{g}^{-1} \min ^{0.5}$ ) and $C$ is the intercept indicating the thickness of nZVMn. The $q_{t}$ is the amount of solute adsorbed per unit weight of adsorbent per time $(\mathrm{mg} / \mathrm{g})$, and $t^{0.5}$ is the half adsorption time (Boparai et al. 2010; Weber and Morris 1963).

\section{Validity of the kinetic data}

The suitability, agreement and best fit among the kinetic models were judged using the statistical validity models such as sum of square error (SSE), Chi-square test $\left(\chi^{2}\right)$ and normalized standard deviation $(\Delta q)$.

The sum of square error (SSE) is the mostly used by researchers. The mathematical expression is given (Foo and Hameed 2010) below:

$\mathrm{SSE}=\sum_{i=1}^{n}\left(q_{\mathrm{e}, \mathrm{cal}}-q_{\mathrm{e}, \mathrm{exp}}\right)^{2}$.

The validity of the kinetic models was also tested using the non-linear Chi-square test. This is a statistical tool necessary for the best fit of an adsorption kinetics system. Better agreement between the experimental data and the calculated quantity adsorbed can be judged using this tool. The mathematical expression is given below:

$\chi^{2}=\sum_{i=1}^{n} \frac{\left(q_{\mathrm{e}, \mathrm{exp}}-q_{\mathrm{e}, \mathrm{cal}}\right)^{2}}{q_{\mathrm{e}, \mathrm{cal}}}$.

The Chi-square test measures the difference between the experimental and model data, where $q_{\mathrm{e}}$, exp is experimental quantity adsorbed at equilibrium and $q_{\mathrm{e}}$,cal is quantity adsorbed calculated from the model equation.
Magnitude of the Chi-square value depends on the agreement between the $q_{\mathrm{e}}$, experimental and the $q_{\mathrm{e}}$, calculated. If data from the model are similar to experimental data, $\chi^{2}$ will be small and if they differ, $\chi^{2}$ will be large (Boparai et al. 2010).

The normalized standard deviation $\Delta q_{t}(\%)$ was calculated using Eq. 16 below (Bello et al. 2014):

$\Delta q(\%)=100 \frac{\sqrt{\sum_{i=1}^{n}\left(\frac{q_{\mathrm{e}, \exp }-q_{\mathrm{e}, \mathrm{cal}}}{q_{\mathrm{e}, \mathrm{exp}}}\right)^{2}}}{n-1}$,

where $n$ is the number of data points and other parameters are the same as earlier defined. Lower value of $\Delta q_{t}$ indicates a good fit between experimental and calculated data (Bello et al. 2014).

\section{Adsorption isotherm model}

An adsorption isotherm is an expression that relates the amount of substance adsorbed per unit mass of the adsorbent to the equilibrium concentration at constant temperature (Foo and Hameed 2010).

\section{Freundlich isotherm model}

The Freundlich adsorption isotherm gives an expression encompassing the surface heterogeneity and the exponential distribution of active sites and their energies. The linear form of Freundlich equation is (Ahmad et al. 2014c; Boparai et al. 2010).

$\log Q_{\mathrm{e}}=\log K_{\mathrm{f}}+1 / n \log C_{e}$.

The Freundlich isotherm constants, $K_{\mathrm{f}}$ and $n_{\mathrm{f}}$ indicating the adsorption capacity and intensity, respectively, are parameters characteristic of the adsorbent-adsorbate system determined from the intercept and slope of the plot of $\log Q_{\mathrm{e}}$ against $\log C_{\mathrm{e}}$.

\section{Langmuir isotherm model}

Langmuir adsorption isotherm assumes a monolayer adsorption onto a homogeneous surface with a finite number of identical sites. There is uniform energy of adsorption onto the surface and no transmigration of adsorbate in the plane of the surface (Ho 2004; Foo and Hameed 2010). The linear form of Langmuir represents:

$\frac{C_{\mathrm{e}}}{Q_{\mathrm{e}}}=\frac{1}{K_{\mathrm{L}} Q_{\max }}+\frac{C_{\mathrm{e}}}{Q_{\max }}$.

$Q_{\max }$ is the maximum monolayer coverage capacity $\left(\mathrm{mg} \mathrm{g}^{-1}\right), \quad K_{\mathrm{L}}$ is the Langmuir isotherm constant $\left(\mathrm{L} \mathrm{mg}^{-1}\right)$ related to the energy of adsorption. The 
essential features of the Langmuir isotherm may be expressed in terms of equilibrium parameter $R_{\mathrm{L}}$, which is a dimensionless constant referred to as separation factor:

$R_{\mathrm{L}}=\frac{1}{1+K_{\mathrm{L}} C_{\mathrm{o}}}$.

$R_{\mathrm{L}}$ value indicates the adsorption nature to either unfavourable or unfavourable.

\section{Temkin isotherm model}

Temkin isotherm contains a factor that explicitly taking into the account of adsorbent-adsorbate interactions. The model assumes that heat of adsorption (function of temperature) of all molecules in the layer would decrease linearly with the surface coverage due to adsorbent-adsorbate interactions. The linear form of the equation is given as (Boparai et al. 2010; Temkin 1940):

$Q_{\mathrm{e}}=\frac{R T}{b_{T}} \ln A_{T}+\frac{R T}{b_{T}} \ln C_{\mathrm{e}}$,

where $B=\mathrm{RT} / b_{T}, b_{T}$ is the Temkin isotherm constant related to the heat of adsorption and $A_{T}$ is the Temkin isotherm equilibrium binding constant $\left(\mathrm{L} \mathrm{g}^{-1}\right)$. The values of theses constants were determined from the slope and intercept obtained from appropriate plot of $Q_{\mathrm{e}}$ versus $\ln C_{\mathrm{e}}$.

\section{Dubinin-Kaganer-Radushkevich (DKR) isotherm model}

DKR isotherm model is generally applied to express the adsorption mechanism with a Gaussian energy distribution onto a heterogeneous surface. The model has often successfully fitted high solute activities and the intermediate range of concentrations data well. The linear equation is given as:

$\ln Q_{e}=\ln Q_{\mathrm{d}}-A_{\mathrm{DKR}} \varepsilon^{2}$,

where $A_{\mathrm{DKR}}$ is the DKR isotherm constant $\left(\mathrm{mol}^{2} / \mathrm{kJ}{ }^{2}\right)$ related to free adsorption energy and $Q_{\mathrm{d}}$ is the theoretical isotherm saturation capacity $(\mathrm{mg} / \mathrm{g})$. The values of $A_{\mathrm{DKR}}$ and $Q_{\mathrm{d}}$ were determined, respectively, from the slope and intercept of the plot of $\ln Q_{\mathrm{e}}$ versus $\varepsilon^{2}$. The parameter $\varepsilon$ is the Polanyi potential which is computed as:

$\varepsilon=R T \ln \left[1+\frac{1}{C_{\mathrm{e}}}\right]$.

The approach was usually applied to distinguish the physical and chemical adsorption of metal ions with its mean adsorption free energy, E per molecule of adsorbate (for removing a molecule from its location in the adsorption space to the infinity) can be computed by the relationship (Bello et al. 2014):
$E=-\left[\frac{1}{\sqrt{2 A_{\mathrm{DKR}}}}\right]$.

\section{Halsey isotherm model}

Halsey isotherm is used to evaluate the multilayer adsorption at a relatively large distance from the surface. The Halsey isotherm model is expressed as (Song et al. 2014; Bhatt and Shah 2013 and Basar 2006).

$\ln q_{\mathrm{e}}=\left[\left(\frac{1}{n_{\mathrm{H}}}\right) \ln K\right]-\left(\frac{1}{n_{\mathrm{H}}}\right) \ln C_{\mathrm{e}}$.

A plot of $\ln q_{\mathrm{e}}$ against $\ln C_{\mathrm{e}}$ should give a linear graph and the Halsey constants $K_{\mathrm{H}}$ and $n_{\mathrm{H}}$ were determined from the intercept and slope, respectively.

\section{Harkin-Jura isotherm model}

The isotherm equation also accounts for multilayer adsorption and can be explained by the existence of heterogeneous pores distribution (Basar 2006; Harkins and Jura 1944). The Harkin-Jura isotherm model is expressed as (Song et al. 2014; Bhatt and Shah 2013):

$\frac{1}{q_{\mathrm{e}}^{2}}=\frac{B_{\mathrm{HJ}}}{A_{\mathrm{HJ}}}-\frac{1}{A_{\mathrm{HJ}}} \log C_{\mathrm{e}}$.

The plot of $\frac{1}{q_{\mathrm{e}}^{2}}$ versus $\log C_{\mathrm{e}}$ should give a straight line hence the Harkin-Jura constants, $A_{\mathrm{HJ}}$ and $B_{\mathrm{HJ}}$, were determined from the slope and intercept of the linear plot.

\section{Flory-Huggins isotherm model}

This is generally used to account for the surface coverage of the adsorbate on the adsorbent. The non-linear and its near expressions are given below (Foo and Hameed 2010; Febrianto et al. 2009):

$\frac{\theta}{C_{\mathrm{o}}}=K_{\mathrm{FH}}(1-\theta)^{n_{\mathrm{FH}}}$,

$\log \left(\frac{\theta}{C_{\mathrm{o}}}\right)=\log K_{\mathrm{FH}}+n_{\mathrm{FH}} \log (1-\theta)$,

where $\theta=1-\left(\frac{C_{\mathrm{e}}}{C_{\mathrm{o}}}\right), \theta$ is the degree of surface coverage, $n_{\mathrm{FH}}$ and $K_{\mathrm{FH}}$ are Flory-Huggin's constants defined as the number of metal ions occupying adsorption sites and the equilibrium constant of adsorption, respectively. They can be determined from the linear plot of $\log \left(\theta / C_{\mathrm{o}}\right)$ versus $\log$ $(1-\theta)$.

\section{Thermodynamic studies}

The data obtained from the effect of temperature at the equilibrium studies were tested with the adsorption 
thermodynamic equations. The thermodynamic parameters can be determined using equations below (Ayanda et al. 2013; Boparai et al. 2010):

$K_{\mathrm{c}}=\frac{q_{\mathrm{e}}}{C_{\mathrm{e}}}$

$\log K_{\mathrm{C}}=\frac{\Delta S^{\circ}}{2.303 R}-\frac{\Delta H^{\circ}}{2.303 R T}$.

The Van't Hoff plot of $\log K_{\mathrm{c}}$ versus $1 / T$ should give a straight line and the thermodynamic parameters, standard enthalpy change $\Delta H^{\circ}\left(\mathrm{kJ} \mathrm{mol}^{-1}\right)$ and standard entropy change $\Delta S^{\circ}\left(\mathrm{J} \mathrm{mol}^{-1} \mathrm{~K}^{-1}\right)$ were determined from the slope and intercept of Eq. 29, respectively. The standard Gibbs free energy $\Delta G^{\circ}\left(\mathrm{KJ} \mathrm{mol}^{-1}\right)$ was calculated using the Eq. 30:

$\Delta G=-2.303 R T \log K_{\mathrm{c}}$.

\section{Results and discussion}

\section{Characterization of $\mathrm{nZVMn}$}

\section{Physicochemical properties of $n Z V M n$}

Table 1 below summarizes the physicochemical properties of nanoscale zerovalent manganese. The $\mathrm{pH}$ of point of zero charge ( $\mathrm{pH}$ PZC) is defined as the $\mathrm{pH}$ at which the surface of nZVMn has a net neutral charge. The $\mathrm{pH}_{(\mathrm{PZC})}$ of nZMn was determined by salt addition method. The significance of this is that nZVMn has negative charge at solution $\mathrm{pH}$ values greater than the pzc and thus a surface

Table 1 Physicochemical parameters of nZVMn

\begin{tabular}{ll}
\hline Characteristics & nZVMn \\
\hline PZC & 5.01 \\
Surface area & \\
BET surface area & $131.3490 \mathrm{~m}^{2} / \mathrm{g}$ \\
$t$ Plot micropore area & $11.3063 \mathrm{~m}^{2} / \mathrm{g}$ \\
$t$ Plot external surface area & $120.0427 \mathrm{~m}^{2} / \mathrm{g}$ \\
BJH adsorption cumulative surface area of pores & \\
Between 17.000 and $3000.000 \AA$ diameter & $132.073 \mathrm{~m}^{2} / \mathrm{g}$ \\
Pore volume & \\
Single point adsorption total pore volume of pores \\
$\quad$ Less than $973.808 \AA$ diameter at $P /$ & $0.559789 \mathrm{~cm}^{3} / \mathrm{g}$ \\
$\quad P_{\mathrm{o}}=0.979706513$ & $0.003846 \mathrm{~cm}^{3} / \mathrm{g}$ \\
$t$ Plot micropore volume & \\
BJH adsorption cumulative volume of pores & $0.611320 \mathrm{~cm}^{3} / \mathrm{g}$ \\
Between 17.000 and $3000.000 \AA$ diameter & \\
Pore size & \\
Adsorption average pore width (4 V/A by BET) & $170.4736 \AA$ \\
BJH adsorption average pore diameter $(4$ V/A) & $185.147 \AA$ \\
\hline
\end{tabular}

on which cations adsorb. The $\mathrm{pH}$ of nZVMn is 5.01 indicating that nZVMn was suitable for the adsorption of $\mathrm{Cu}^{2+}$ at a pH above 5.01 (Jaafar et al. 2013; Srivastava et al. 2005).

From the BET result (Table 1), the surface area of nZVMn is $131.3490 \mathrm{~m}^{2} / \mathrm{g}, t$ plot micropore area is $11.3063 \mathrm{~m}^{2} / \mathrm{g}, t$ plot external surface area is $120.0427 \mathrm{~m}^{2} /$ g. The BJH adsorption cumulative surface area of pores between 17.000 and $3000.000 \AA$ diameter is $132.073 \mathrm{~m}^{2} / \mathrm{g}$. The single point adsorption total pore volume of pores less than $973.808 \AA$ diameter at $P / P_{\mathrm{o}}=0.979706513$ is $0.559789 \mathrm{~cm}^{3} / \mathrm{g}$. $t$ plot micropore volume is $0.003846 \mathrm{~cm}^{3} /$ g. The BJH adsorption cumulative volume of pores between 17.000 and $3000.000 \AA$ diameter is $0.611320 \mathrm{~cm}^{3} / \mathrm{g}$. The adsorption average pore width $(4 \mathrm{~V} /$ A by BET) is $170.4736 \AA$. The BJH adsorption average pore diameter $(4 \mathrm{~V} / \mathrm{A})$ is $185.147 \AA$. The relatively higher value of the external surface area compared to the micropore surface area implies that nZVMn utilized its external surface for adsorption than its micropore.

\section{UV-VIS analysis}

The reduction of $\mathrm{Mn}^{2+}$ to $\mathrm{Mn}^{0}$ (nZVMn) by sodium borohydride was monitored using a Beckmann Coulter DU 730 Life Science UV-VIS spectrophotometer. A small aliquot was drawn from the reaction mixture and a spectrum was taken at a wavelength from 200 to $800 \mathrm{~nm}$.

The adsorption spectrum of nZVMn as presented in Fig. 1 showed the maximum wavelength was observed at about $380 \mathrm{~nm}$. This is an indication of surface plasmon resonance which is the collective oscillation of the conduction of electron in resonance with light due to electron conferment in nZVMn. The SPR depends mainly on the nature of the metal, the morphology of the nanoparticles and the dielectric properties of the environment or medium of dispersion (Jain et al. 2007; Waghmare et al. 2011).

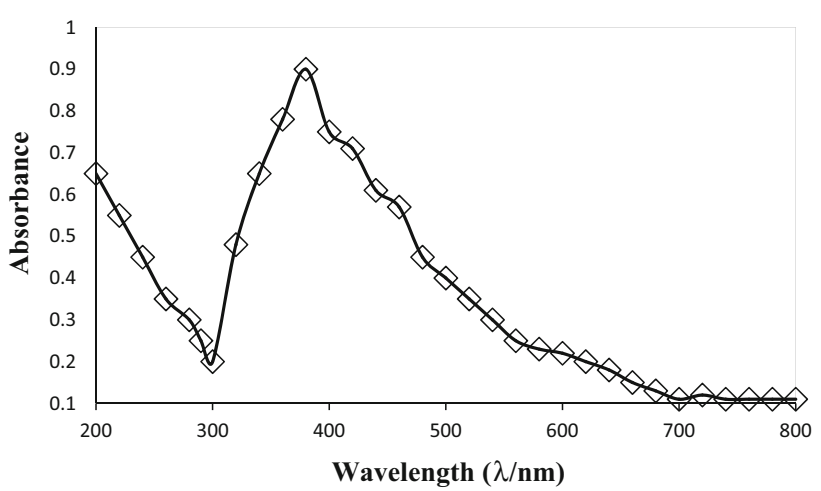

Fig. 1 UV-VIS spectrum of nZVMn 
Fig. 2 FT-IR spectrum of nZVMn

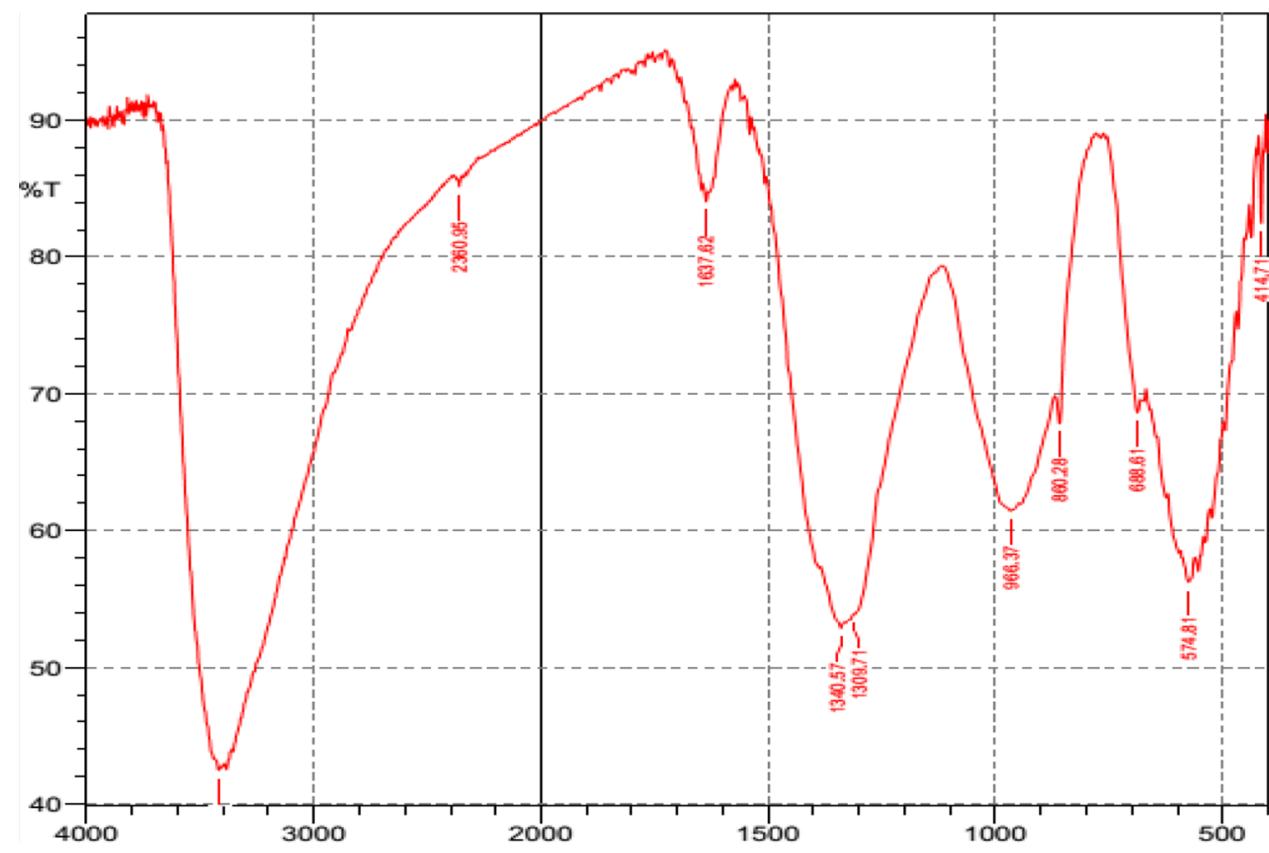

\section{FTIR analysis}

Figure 2 below presents FTIR spectrum of manganese nanoparticles with some characteristic vibration bands at $3288,1636,1307$, and $504 \mathrm{~cm}^{-1}$. The peak at $3288 \mathrm{~cm}^{-1}$ stands for $\mathrm{O}-\mathrm{H}$ broad of alcohol from the medium of dispersion of nZVMn where the manganese nanoparticle was kept for preservation, $\mathrm{H}-\mathrm{O}-\mathrm{H}$ stretching $\left(1636 \mathrm{~cm}^{-1}\right), \mathrm{C}-$ $\mathrm{O}$ stretching of alcohol at $1309 \mathrm{~cm}^{-1}$ and the peak at $504 \mathrm{~cm}^{-1}$ corresponds to nZVMn as summarized in Table 2 below (Sinha et al. 2011; Li et al. 2009).

\section{TEM analysis}

TEM micrograph in Fig. 3 reveals the micro-images of nanoscale zerovalent manganese (nZVMn) of size range $6.120-99.428 \mathrm{~nm}$.

The traces of dispersions and whiskers which are attributes of manganese nanoparticles were observed. This is in agreement with the finding of Lisha et al. 2010.

Table 2 Summary of the functional groups and vibration frequencies on the IR spectrum of nZVMn

\begin{tabular}{ll}
\hline Functional group & Vibration bands $\left(\mathrm{cm}^{-1}\right)$ \\
\hline O-H str of alcohol & 3288 \\
H-O-H str & 1636 \\
-C-O & 1309 \\
nZVMn & 504 \\
\hline
\end{tabular}

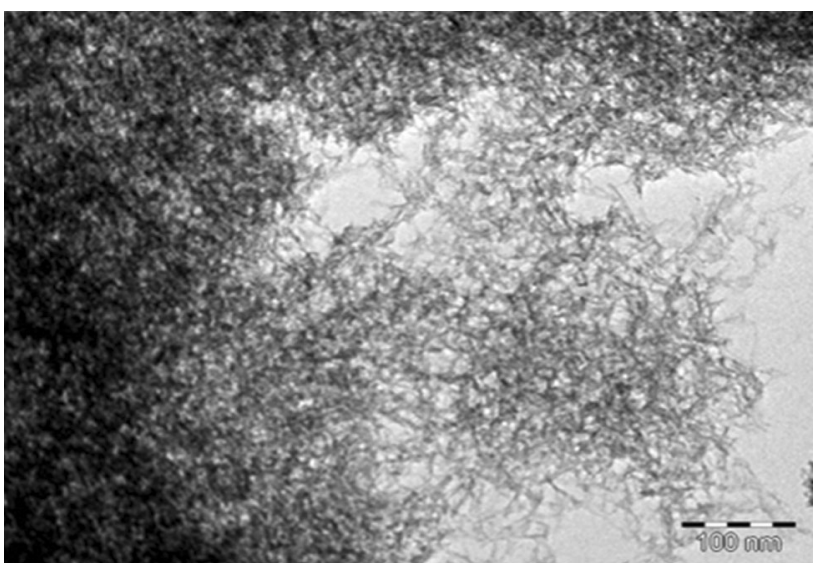

Fig. 3 TEM of nZVMn

\section{Effect of ZVMn dose, agitation speed and contact time}

Optimization of the amount of zerovalent manganese nanoparticles needed for the adsorption of $\mathrm{Cu}^{2+}$ was carried out. It was observed that the percentage of $\mathrm{Cu}^{2+}$ removed increased with an increase in the adsorbent dose. The removal efficiency increased from $91.6 \%$ at $50 \mathrm{mg}$ to $100 \%$ at $100 \mathrm{mg}$ due to an increase in the number of available adsorption sites and large surface area of nZVMn as shown in Fig. 4. The adsorbent (nZVMn) became saturated with $\mathrm{Cu}^{2+}$ and the residual concentrations increased at adsorbent dose less than $100 \mathrm{mg}$ until a saturated point was reached. Above $100 \mathrm{mg}$, there was relatively no significant increase in the quantity adsorbed because all the 


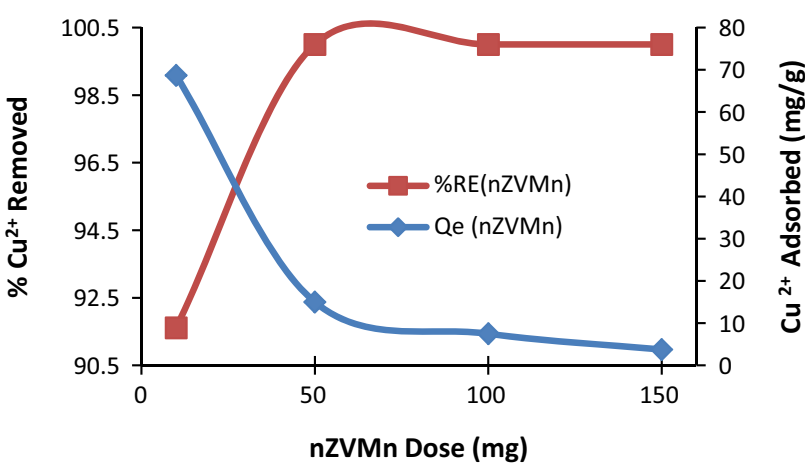

Fig. 4 Effect of nZVMn dose on $\mathrm{Cu}^{2+}$ adsorbed by nZVMn. Experimental conditions: optimum $\mathrm{Cu}^{2+}$ concentration $=100 \mathrm{ppm}$; volume of $\mathrm{Cu}^{2+}$ solution $=50 \mathrm{~mL} ; \mathrm{pH}=5$, stirring speed $=200 \mathrm{rpm}$, contact time $=60 \mathrm{~min}$, and temperature $=25 \pm 2{ }^{\circ} \mathrm{C}$

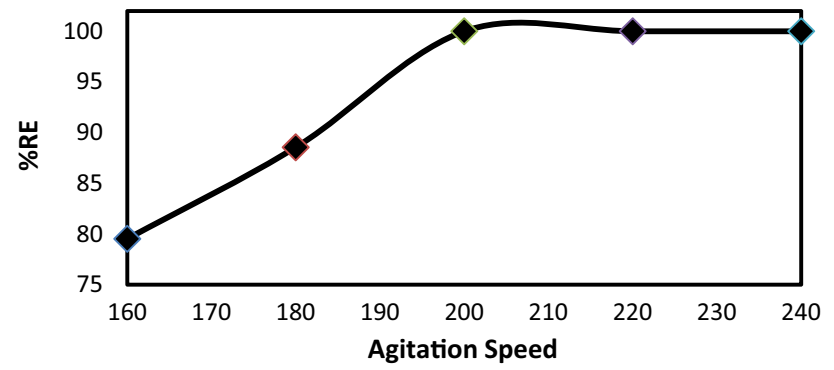

Fig. 5 Effect of agitation speed on $\mathrm{Cu}^{2+}$ adsorbed onto nZVMn. Experimental conditions: optimum $\mathrm{Cu}^{2+}$ concentration $=100 \mathrm{ppm}$; volume of $\mathrm{Cu}^{2+}$ solution $=50 \mathrm{~mL} ;$ nZVMn dose $=100 \mathrm{mg}$; $\mathrm{pH}=5$, contact time $=60 \mathrm{~min}$, and temperature $=25 \pm 2{ }^{\circ} \mathrm{C}$

active sites had been saturated and the quantity adsorbed decreased. This finding is in agreement with the reports of Hao et al. (2010); Srivastava et al. (2005).

Agitation speed (Fig. 5) plays an important role in adsorption studies because it promotes turbulence, frequency of collision and improves mass transfer in the medium between the two phases (Larous et al. 2005). To optimize agitation speed, five different speeds were chosen between 160 and $240 \mathrm{rpm}$, as shown in Fig. 5. It was observed that removal efficiency increased from $79.52 \%$ to $100 \%$ with an increase in the agitation speed. It increased until maximum removal efficiency was obtained at $200 \mathrm{rpm}$ above which there was no significant increase. Other adsorption studies were carried out at this optimum agitation speed. This finding is in agreement with the report of Ayanda et al. 2013.

Contact time (Fig. 6) is another important factor in all transfer phenomena such as adsorption. A short contact time to reach equilibrium indicates the fast transport of metal ions from the bulk to the outer and inner surface of nZVMn. In addition, contact time also controls the buildup of charges at the solid-liquid interfaces and for this reason,

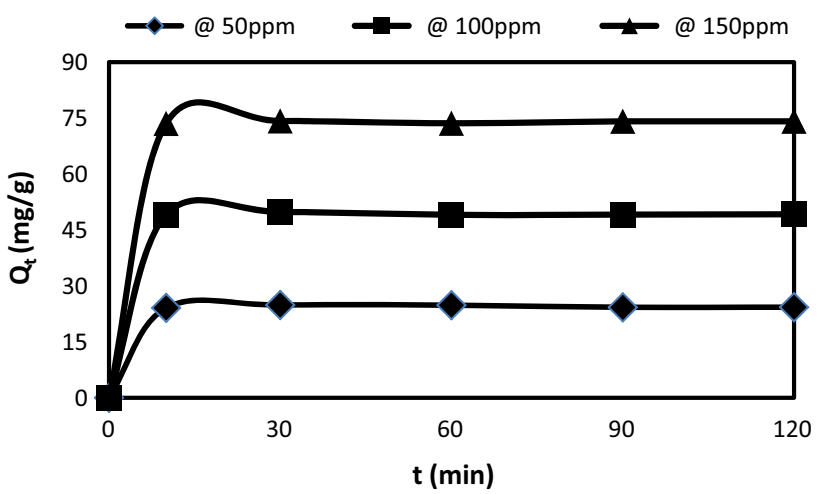

Fig. 6 Effect of contact time on $\mathrm{Cu}^{2+}$ adsorbed onto nZVMn. Experimental conditions: $\mathrm{Cu}^{2+}$ concentration $=100 \mathrm{ppm}$; volume of $\mathrm{Cu}^{2+}$ solution $=50 \mathrm{~mL} ; \mathrm{nZVMn}$ dose $=100 \mathrm{mg} ; \mathrm{pH}=5$, stirring speed $=200 \mathrm{rpm}$, and temperature $=25 \pm 2{ }^{\circ} \mathrm{C}$

optimization of the effect of contact time on the adsorption of $\mathrm{Cu}^{2+}$ onto $\mathrm{nZVMn}$ was investigated at three different concentrations $50 \mathrm{ppm}, 100 \mathrm{ppm}$ and $150 \mathrm{ppm}$ from $10 \mathrm{~min}$ to $120 \mathrm{~min}$. The rate of adsorption and equilibrium was attained between 30 and 60 min with $39.85,59.76$ and $99.2 \mathrm{mg} / \mathrm{g}$ quantity adsorbed as shown in Fig. 6. The optimum contact time observed was 60 min after which as steady-state approximation set in and a quasi-equilibrium situation was attained (Srivastava et al. 2005). All other operational parameters were studied at 60 -min contact time.

\section{Adsorption kinetics and mechanism of reaction}

The kinetic studies vis-à-vis pseudo first-order, pseudo second-order, Elovich, Fractional power, intraparticle diffusion plots are shown in Figs. 7, 8, 9, 10 and 11,

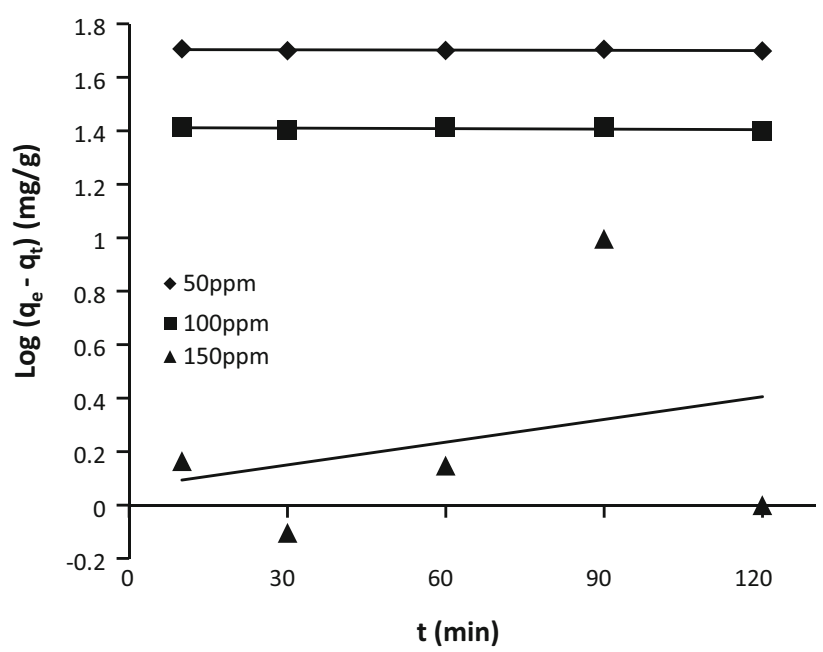

Fig. 7 Pseudo first-order kinetics plot for sorption of $\mathrm{Cu}^{2+}$ onto nZVMn 


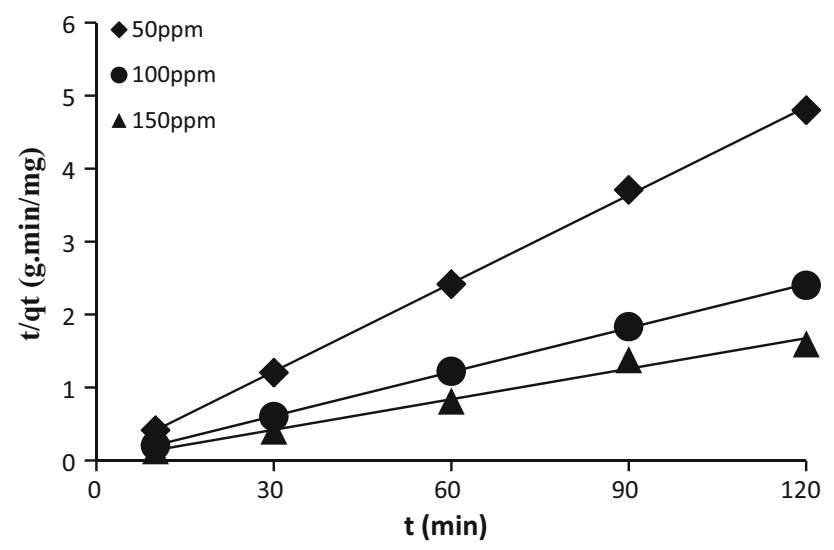

Fig. 8 Pseudo second-order kinetics plot for sorption of $\mathrm{Cu}^{2+}$ onto nZVMn

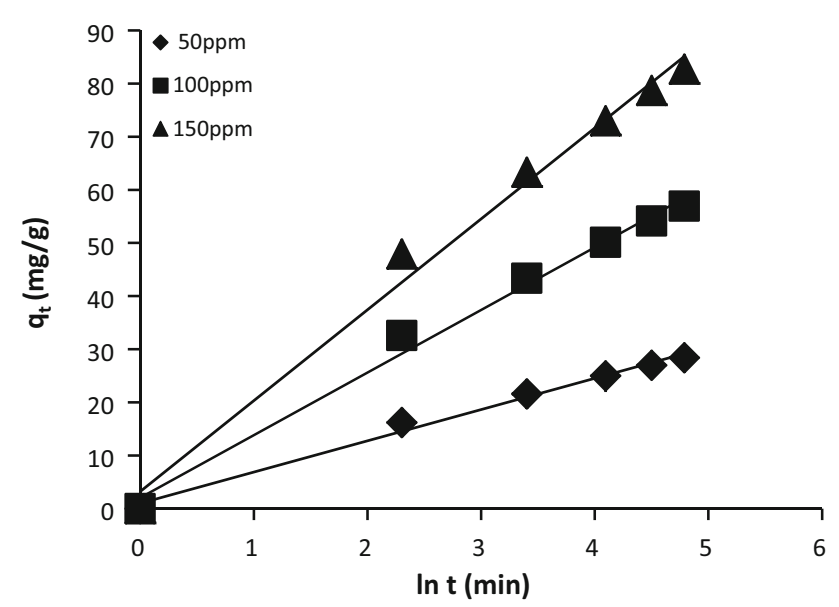

Fig. 9 Elovich kinetics model plot for sorption of $\mathrm{Cu}^{2+}$ nZVMn

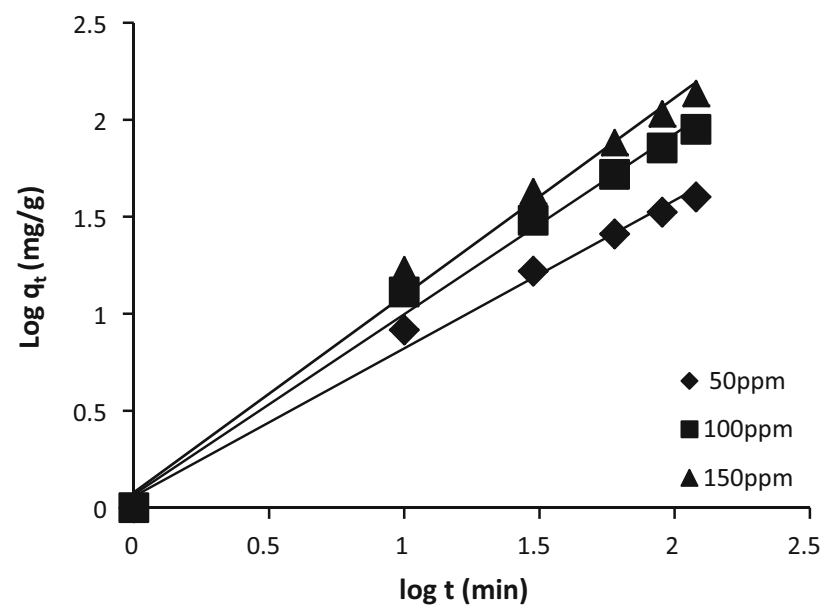

Fig. 10 Fractional power rate equation plot for onto $\mathrm{Cu}^{2+}$ onto nZVMn

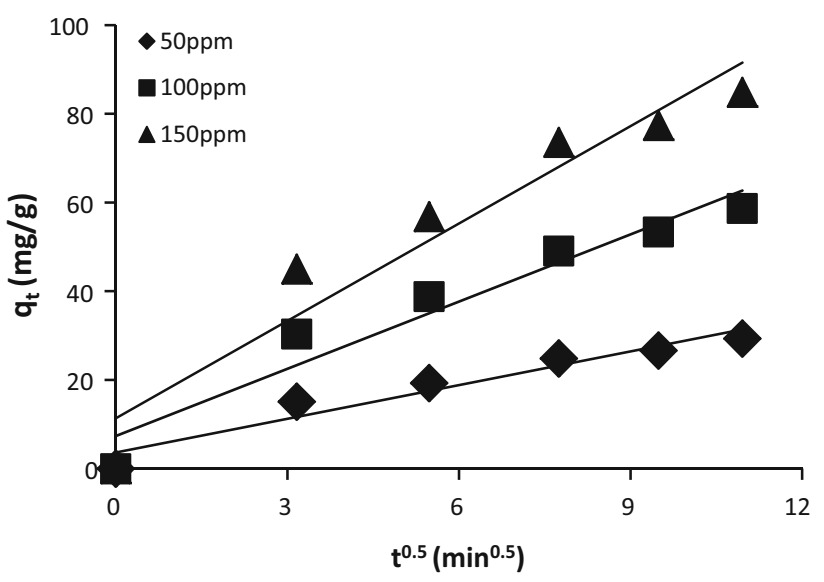

Fig. 11 Intraparticle diffusion plot for sorption of $\mathrm{Cu}^{2+}$ onto nZVMn

respectively. The evaluated parameters from these kinetic models are well stated in Table 3. From the regression coefficient $\left(R^{2}\right)$ point of view, the adsorption kinetics data were well described by pseudo second-order kinetics having $R^{2}>0.99$ (Fig. 8). Considering Table 3, the rate of reaction, $h_{2}$ for pseudo second order was distinctly higher than that of pseudo first order. The experimental quantity adsorbed and the calculated quantity adsorbed ( $q_{\mathrm{e}, \exp }$ and $\left.q_{\mathrm{e}, \mathrm{cal}}\right)$ from pseudo second-order kinetics were in close agreement suggesting that the kinetic data from the adsorption of $\mathrm{Cu}^{2+}$ fitted well to pseudo second-order model.

Shown in Fig. 9 is the linear plot of Elovich model. This model describes adsorption on highly heterogeneous adsorbent (Hao et al. 2010). The values of $\alpha$ (adsorption rate) (Table 3) increase with an increase in concentration as a result of increase in the number of sites. The values $1 / \beta$ at $50 \mathrm{ppm}, 100$ and $150 \mathrm{ppm}$ are 5.882, 11.764 and 17.123, respectively. These values reflected the number of sites available for adsorption (Ahmad et al. 2014b, Song et al. 2014).

The parameters of fractional power (Fig. 10) were evaluated at different concentrations from the plot of $\log \left(q_{t}\right)$ versus $\log (t)$ in Eq. 12 and the values of $R^{2}(0.991$, 0.991 and 0.989 ) showed that the kinetic data fitted also well to the fractional power model.

Adequate understanding of the adsorption mechanism is enhanced by the determination of the rate-controlling/determining step. The three definite steps that could be used to describe the adsorption rate are (Boparai et al. 2010; Chingombe et al. 2006): (1) Intraparticle or pore diffusion, where adsorbate molecules percolates into the interior of adsorbent particles, (2) liquid film or surface diffusion where the adsorbate is transported from the bulk solution to 
Table 3 Kinetics model parameters for the sorption of different initial concentrations $\mathrm{Cu}^{2+}$ onto nZVMn

\begin{tabular}{|c|c|c|c|}
\hline \multirow{2}{*}{$\begin{array}{l}\text { Kinetics model } \\
\text { parameters }\end{array}$} & \multicolumn{3}{|c|}{ Initial metal ion concentrations } \\
\hline & $50 \mathrm{ppm}$ & $100 \mathrm{ppm}$ & $150 \mathrm{ppm}$ \\
\hline \multicolumn{4}{|l|}{ Pseudo first order } \\
\hline$q_{\mathrm{e}}, \exp (\mathrm{mg} / \mathrm{g})$ & 24.843 & 49.069 & 73.593 \\
\hline$q_{\mathrm{e}}, \mathrm{cal}(\mathrm{mg} / \mathrm{g})$ & 50.606 & 25.823 & 1.163 \\
\hline$k_{1}\left(\min ^{-1}\right)$ & $6.909 \times 10^{-5}$ & $1.612 \times 10^{-4}$ & 0.0645 \\
\hline$h_{1}(\mathrm{mg} / \mathrm{g} / \mathrm{min})$ & $3.496 \times 10^{-3}$ & $4.163 \times 10^{-3}$ & 0.075 \\
\hline$R^{2}$ & 0.169 & 0.145 & 0.0831 \\
\hline SSE & 663.73 & 540.376 & 5246.11 \\
\hline$\chi^{2}$ & 13.116 & 20.926 & 4510.838 \\
\hline$\Delta q$ & 20.741 & 9.475 & 19.684 \\
\hline \multicolumn{4}{|l|}{ Pseudo second order } \\
\hline$q_{\mathrm{e}}, \exp (\mathrm{mg} / \mathrm{g})$ & 24.843 & 49.069 & 73.593 \\
\hline$q_{\mathrm{e}}, \mathrm{cal}(\mathrm{mg} / \mathrm{g})$ & 24.813 & 49.751 & 71.942 \\
\hline$k_{2}(\mathrm{~g} / \mathrm{mg} / \mathrm{min})$ & 0.1299 & 0.05386 & 0.00254 \\
\hline$h_{2}(\mathrm{mg} / \mathrm{g} / \mathrm{min})$ & 79.977 & 133.332 & 15.288 \\
\hline$R^{2}$ & 0.999 & 0.999 & 0.986 \\
\hline SSE & 0.0009 & 0.465 & 2.726 \\
\hline$\chi^{2}$ & $3.627 \times 10^{-5}$ & $9.3490 \times 10^{-3}$ & $3.823 \times 10^{-2}$ \\
\hline$\Delta q$ & 0.024 & 0.278 & 0.449 \\
\hline \multicolumn{4}{|l|}{ Elovich } \\
\hline$\alpha\left(\mathrm{g} \min ^{2} / \mathrm{mg}\right)$ & 6.696 & 13.996 & 20.668 \\
\hline$\beta(\mathrm{g} \mathrm{min} / \mathrm{mg})$ & 0.17 & 0.085 & 0.0584 \\
\hline$R^{2}$ & 0.991 & 0.991 & 0.986 \\
\hline SSE & 0.0557 & 1.449 & 0.122 \\
\hline$\chi^{2}$ & $2.22 \times 10^{-3}$ & $2.88 \times 10^{-2}$ & $1.66 \times 10^{-2}$ \\
\hline$\Delta q$ & 0.189 & 0.491 & 0.0948 \\
\hline \multicolumn{4}{|l|}{ Fractional power } \\
\hline$v\left(\min ^{-1}\right)$ & 0.764 & 0.93 & 1.017 \\
\hline$k_{3}(\mathrm{mg} / \mathrm{g})$ & 1.142 & 1.17 & 1.199 \\
\hline$k_{3} v(\mathrm{mg} / \mathrm{g} / \mathrm{min})$ & 0.872 & 0.158 & 1.22 \\
\hline$R^{2}$ & 0.991 & 0.991 & 0.99 \\
\hline$S S E$ & 1.383 & 12.559 & 13.374 \\
\hline$\chi^{2}$ & 0.053 & 0.239 & 0.0172 \\
\hline$\Delta q$ & 0.056 & 1.444 & 0.994 \\
\hline \multicolumn{4}{|c|}{ Intraparticle diffusion } \\
\hline$k_{\mathrm{ip}}\left(\mathrm{mg} / \mathrm{g} / \mathrm{min}^{0.5}\right)$ & 2.534 & 5.054 & 7.323 \\
\hline$C$ & 3.646 & 7.357 & 11.34 \\
\hline$R^{2}$ & 0.937 & 0.937 & 0.927 \\
\hline SSE & 2.462 & 6.579 & 30.548 \\
\hline$\chi^{2}$ & 0.106 & 0.141 & 0.449 \\
\hline$\Delta q$ & 1.982 & 1.045 & 1.502 \\
\hline
\end{tabular}

the external surface of adsorbent, and (3) adsorption on the interior sites of the sorbent. Since the rate of reaction from the pseudo second order is very high, it shows that the adsorption rate was very fast and hence it is assumed that it does not only influence the overall kinetics. The rate of adsorption could also be controlled by intraparticle. The Weber-Morris intraparticle diffusion model has often been used to verify if intraparticle diffusion is the rate-limiting step (Igwe et al. 2005). In this study, the intraparticle diffusion (Fig. 11) shows a linear plot of $\left(q_{t}\right)$ versus $\left(t^{0.5}\right)$ from Eq. 13 where $k_{\text {id }}$ (intraparticle diffusion rate constant) and $C$ (thickness of the surface) were determined from the slope and intercept. The intercept which is the thickness of the surface gave information about contribution of the surface adsorption in the rate-determining step. The larger the intercept, the greater is its contribution. The linear plot of $\mathrm{q}_{t}$ versus $t^{1 / 2}$ suggested that adsorption of $\mathrm{Cu}^{2+}$ was governed by pore diffusion. Since the plot of $q_{t}$ versus $t^{0.5}$ did not pass through the origin, it indicated that intraparticle is not the only rate-determining step (Ahmad et al. 2014c; Igwe and Abia 2006; Wu et al. 2001). It is suggested that other steps like external diffusion and liquid film diffusion may the involved in the rate-determining steps.

A strong confirmation that the adsorbate $\left(\mathrm{Cu}^{2+}\right)$ had percolated into the pores and surface of the nZVMn was provided by the SEM and EDX analyses shown in Fig. 12a-d. The morphological characterization was done before and after adsorption of $\mathrm{Cu}^{2+}$ onto nZVMn. Figure 12a depicts the SEM micrograph of zerovalent manganese nanoparticle before adsorption. Before adsorption, SEM spectrum reveals coarse, rough and crake surface which is an indication of high surface area and presence of pores for uptake of $\mathrm{Cu}^{2+}$. The presence of cracks surface enhanced free and dynamic flow of the adsorbate into the pores of nZVMn. Also, the rough and coarseness of the surface indicating a higher surface area facilitated strong adsorption of $\mathrm{Cu}^{2+}$ into the pores and external surface of nZVMn nano-adsorbent (Morsali et al. 2011). The SEM (Fig. 12b) micrograph after adsorption reveals that the surface of the nano-adsorbent had changed, the traces of cracks were finally eliminated by the flow of $\mathrm{Cu}^{2+}$ solution. The $\mathrm{Cu}^{2+}$ had percolated on the surface of $n Z V M n$ and evidence is seen by the robust nature of the nZVMn after adsorption.

The EDX spectra (Fig. 12c-d) give information on the surface atomic distribution and the chemical elemental composition of nZVMn. Figure 12c shows the prominent peaks of manganese nanoparticles and at 0.8 and $6.0 \mathrm{keV}$ energy dispersions. The presence of copper before adsorption arose from the copper grid used during the analysis, other elements may arise from the traces of additives used during the analysis. Nevertheless, the presence of copper as shown in Fig. 12d came from the $\mathrm{Cu}^{2+}$ solution (Sinha et al. 2011; Waghmare et al. 2011; Lisha et al. 2010). 

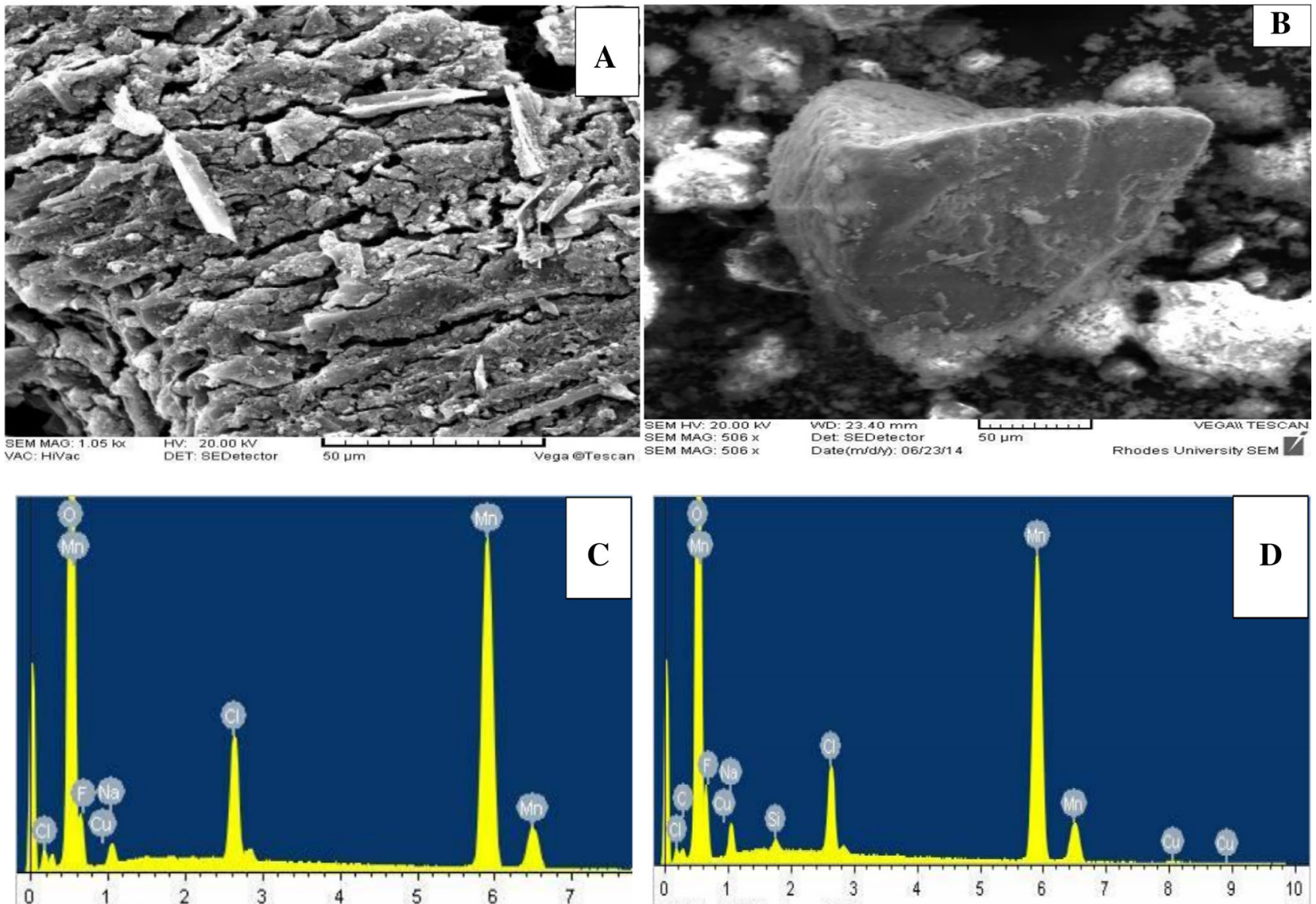

Full Scale 4385 cts Cursor: 0.000

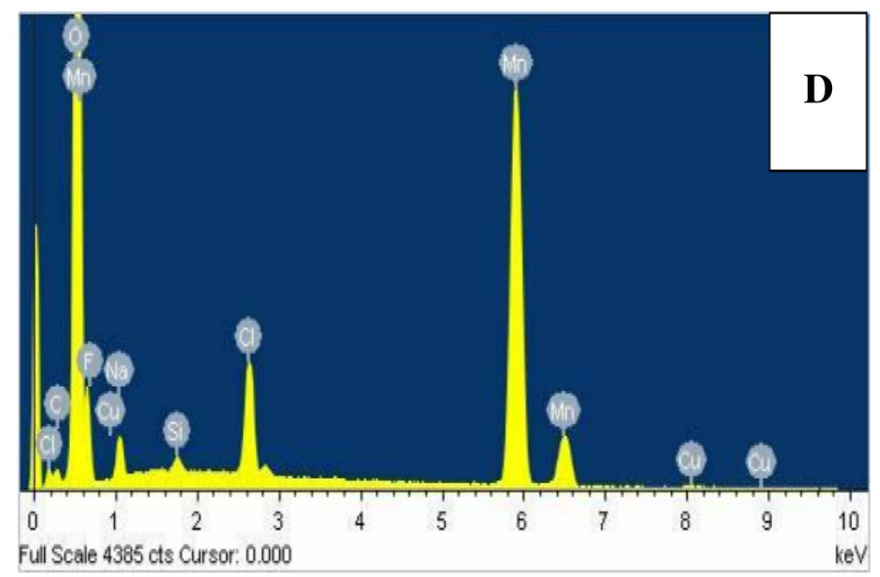

Fig. 12 (a) SEM image of nZVMn before sorption (b) SEM image of nZVMn after sorption (c) EDXspectrum of nZVMn before sorption, (d) EDX spectrum of $\mathrm{Cu}(\mathrm{II})$ loaded nZVMn after sorption

\section{Validity test on the kinetics data}

The kinetics data were validated using three statistical models namely: sum of square error (SSE), Chi-square test $\left(\chi^{2}\right)$, and normalized standard deviation $(\Delta q)$. The evaluated data are also summarized in Table 3 . The applicability of these kinetics models (pseudo first order, pseudo second order, Elovich, fractional power and intraparticle diffusion) was judged by comparing the $R^{2}$ values with SSE, Chisquare $\left(\chi^{2}\right)$ and normalized standard deviation $(\Delta q) \%$. The closer the value of $R^{2}$ to unity, the lower the value of SSE, $\chi^{2}$ and $\Delta q$, the better the model in describing the adsorption of $\mathrm{Cu}^{2+}$ onto nZVMn. Pseudo second order perfectly fitted to this while poor description was obtained in pseudo firstorder parameters. This finding is supported by the report from the literature (Ahmad et al. 2014a, b, c; Bello et al. 2014; Song et al. 2014; Bhatt and Shah 2013; Hao et al. 2010; Foo and Hameed 2010).

\section{Effect of pH}

Effect of $\mathrm{pH}$ plays one of the greatest roles in the adsorption studies because it influences the surface charge of the adsorbents, ionic mobility, the degree of ionization and speciation of different pollutants and solution chemistry of contaminants (i.e. hydrolysis, redox reactions, polymerization and coordination) (Ren et al. 2008). It has been reported that $\mathrm{Cu}(\mathrm{II})$ in aqueous solution exists in different forms such as $\mathrm{Cu}^{2+}, \mathrm{Cu}(\mathrm{OH})^{+}, \mathrm{Cu}(\mathrm{OH})_{2}, \mathrm{Cu}(\mathrm{OH})_{3}^{-}$and $\mathrm{Cu}(\mathrm{OH})_{4}{ }^{2-}$ and the predominant copper species at $\mathrm{pH}<6.0$ is $\mathrm{Cu}^{2+}$ (Badruddoza et al. 2011; Xu et al. 2006).

Optimum $\mathrm{pH}$ was attained at 5 with the percentage removal $>99 \%$. However, at lower $\mathrm{pH}$ between 1 and 3 , in acidic medium, protonation occurs and electrostatic competition sprout up between $\mathrm{Cu}^{2+}$ and other protonated species like $\mathrm{H}^{+}$for the available adsorption sites. This competition reduced as soon as the $\mathrm{pH}$ approaches neu- 


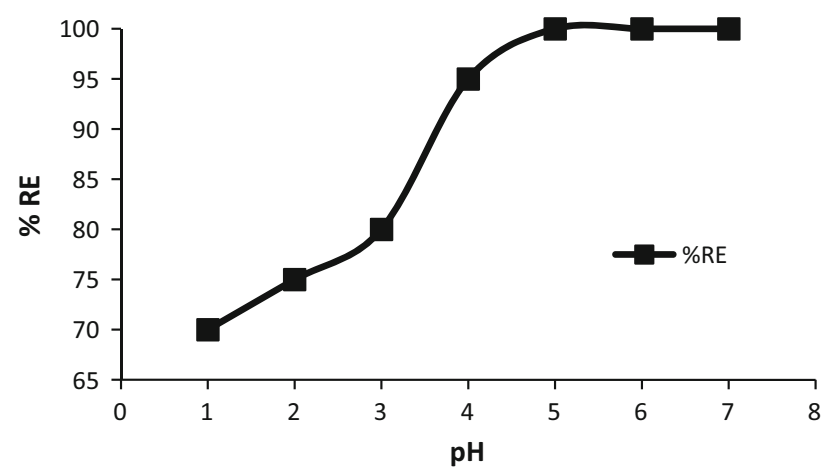

Fig. 13 Effect of $\mathrm{pH}$ on $\mathrm{Cu}^{2+}$ adsorbed onto nZVMn. Experimental conditions: optimum $\mathrm{Cu}^{2+}$ concentration $=100 \mathrm{ppm}$; volume of $\mathrm{Cu}^{2+} \quad$ solution $=50 \mathrm{~mL} ; \quad$ nZVMn $\quad$ dose $=100 \mathrm{mg} ; \quad$ stirring speed $=200 \mathrm{rpm}$, contact time $=60 \mathrm{~min}$

trality and tending towards alkaline medium where deprotonation occurs. At this point, percentage of $\mathrm{Cu}^{2+}$ removed increase because the competition for the available adsorption sites had reduced. Maximum values of the percentage and the quantity removed were observed at $\mathrm{pH}$ 5 (Fig. 13). This is supported by the finding of Badruddoza et al. 2011; Xiao et al. 2011; Kara and Demirbel 2012; Cai et al. 2014; Sikdera et al. 2014; Gonga et al. 2012; Cho et al. 2012; Karabellia et al. 2011; White et al. 2009; Zhou et al. 2009; Huang and Chen 2009; Doğan et al. 2009).

\section{Adsorption isotherm}

The effect of initial concentration as shown in Fig. 14 was studied from 10 to $200 \mathrm{ppm}$. At a lower concentration, the percentage removal efficiency increases because of the availability of more active sites until the adsorption sites are saturated at $100 \mathrm{ppm}$ above which there was no significant increase in the quantity adsorbed and percentage removal efficiency. The increase in adsorption capacity

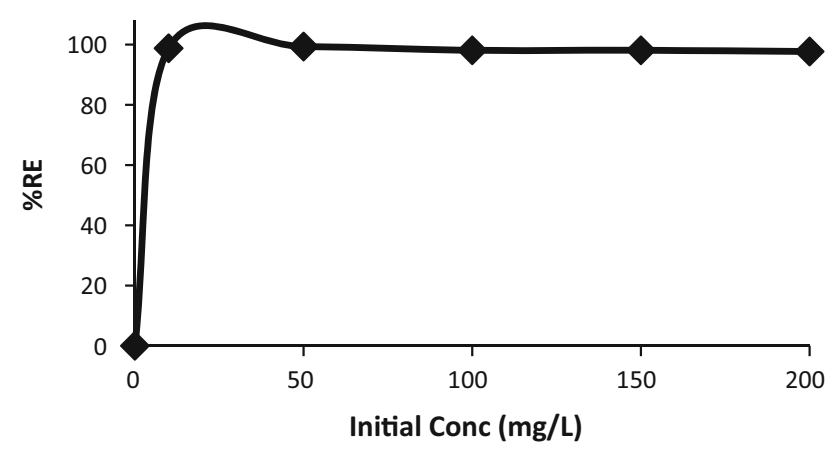

Fig. 14 Effect of initial concentration on $\mathrm{Cu}^{2+}$ adsorbed onto nZVMn. Experimental conditions: optimum $\mathrm{Cu}^{2+}$ concentration $=100 \mathrm{ppm}$; volume of $\mathrm{Cu}^{2+}$ solution $=50 \mathrm{~mL} ; \mathrm{nZVMn}$ dose $=100 \mathrm{mg} ; \mathrm{pH}=5$, contact time $=60 \mathrm{~min}$, and temperature $=25 \pm 2{ }^{\circ} \mathrm{C}$ from 4.935 to $93.737 \mathrm{mg} / \mathrm{g}$ with an increase in initial $\mathrm{Cu}^{2+}$ concentration from 10 to $200 \mathrm{ppm}$ was as a result of the increase in driving force due to the concentration gradient developed between the bulk solution and surface of the nZVMn nano-adsorbent (Kumar et al. 2010). At higher $\mathrm{Cu}^{2+}$ concentrations, the active sites of the adsorbents were surrounded by more $\mathrm{Cu}^{2+}$ and the process of adsorption continued until equilibrium was reached.

The adsorption isotherms provide information and insight into the relationship between the adsorbate and the adsorbent. In this research, adsorption data were tested with seven different isotherms models: Langmuir, Freundlich, Temkin, DKR, Halsey, Harkin-Jura, Flory-Huggins as shown in Figs. 15, 16, 17, 18, 19, 20 and 21. The summary of the evaluated parameters and the correlation coefficients are stated in Table 4. Based on the correlation coefficients, the equilibrium adsorption data fitted better into Freundlich, Langmuir, Temkin, DRK and Halsey models. Figure 15 shows the Freundlich plot for adsorption of $\mathrm{Cu}^{2+}$ onto nZVMn. The constants $K_{\mathrm{F}}$ and $\mathrm{n}$ were determined from the plot of $\log Q_{\mathrm{e}}$ versus $\log C_{\mathrm{e}} .1 / n$ is a heterogeneity parameter. In this study, the value of $n$ (Table 4) is 1.352 which is less than 10 indicating a favourable adsorption (Foo and Hameed 2010).

The Langmuir constants (Fig. 16a; Table 4), $Q_{\max }$ (maximum monolayer coverage capacity), and $K_{\mathrm{L}}$ (Langmuir isotherm constant related to the energy of adsorption) were determined from the linear plot of $C_{\mathrm{e}} / Q_{\mathrm{e}}$ against $C_{\mathrm{e}}$ in Eq. 18.

The essential feature of the Langmuir isotherm may be expressed in terms of equilibrium parameter $R_{\mathrm{L}}$ (Fig. 16b) which is a dimensionless constant referred to as separation factor or equilibrium parameter (Hao et al. 2010). The value of $R_{\mathrm{L}}$ is an important indicator to determine if adsorption will be favourable or unfavourable. If $R_{\mathrm{L}}>1$, it is unfavourable, if $R_{\mathrm{L}}=1$, it is linear, if $0<R_{\mathrm{L}}<1$ it is favourable and irreversible if $R_{\mathrm{L}}=0$. The values of $R_{\mathrm{L}}$

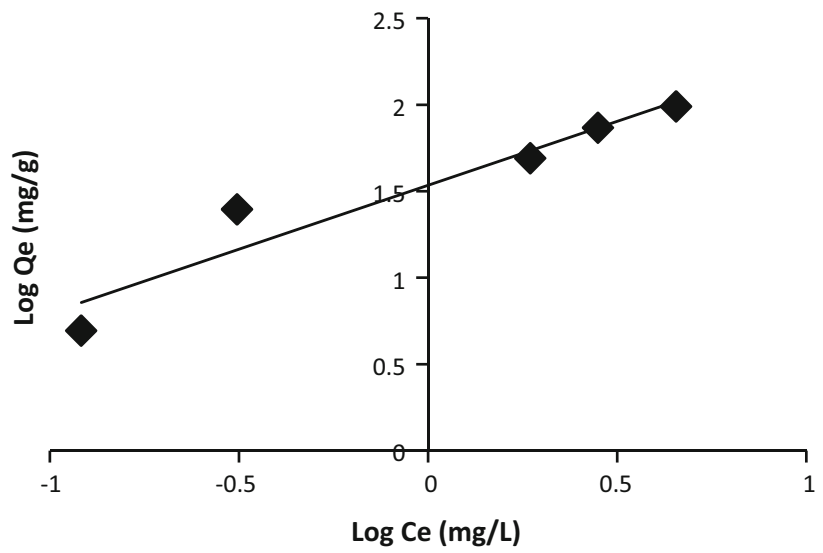

Fig. 15 Freundlich isotherm model for sorption of $\mathrm{Cu}^{2+}$ onto nZVMn

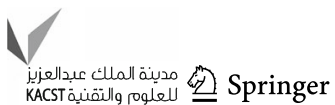



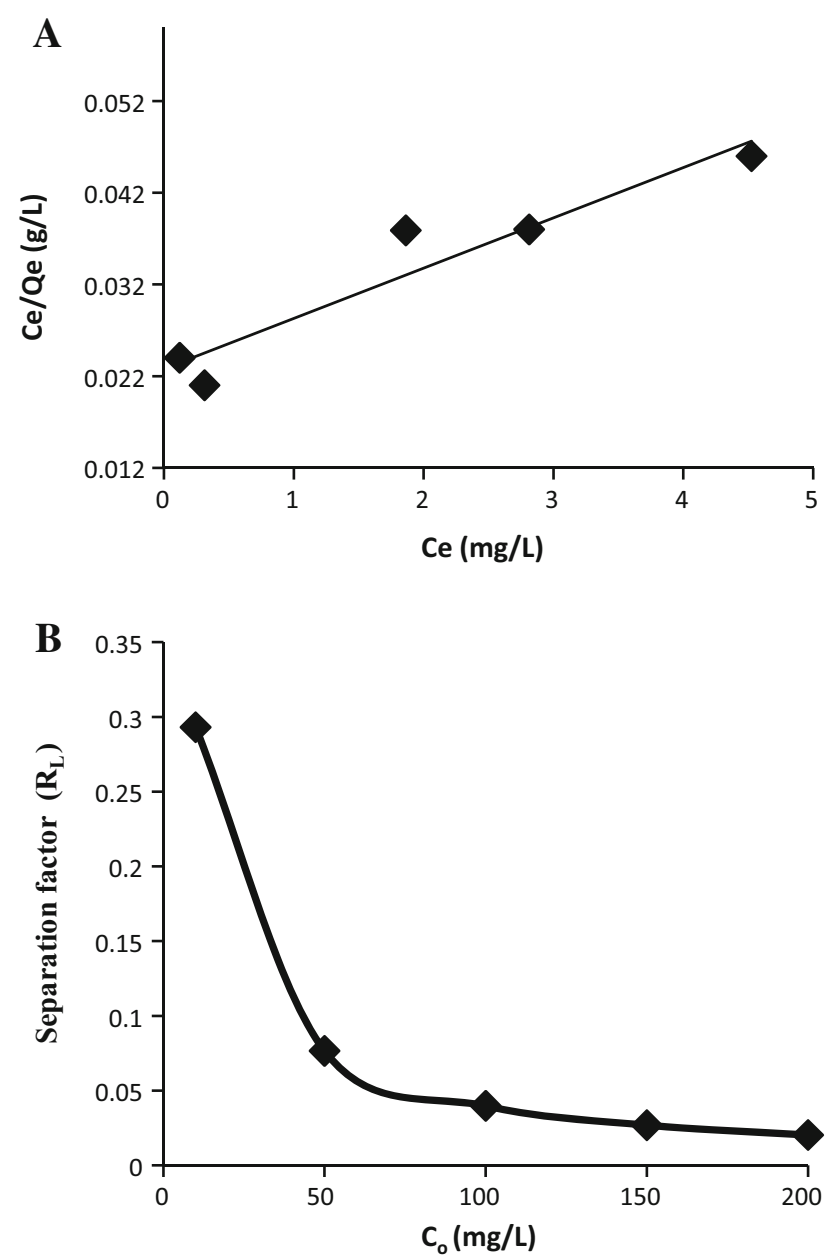

Fig. 16 a Langmuir isotherm model for sorption of $\mathrm{Cu}^{2+}$ onto nZVMn, b separation factor on sorption of $\mathrm{Cu}^{2+}$ onto nZVM

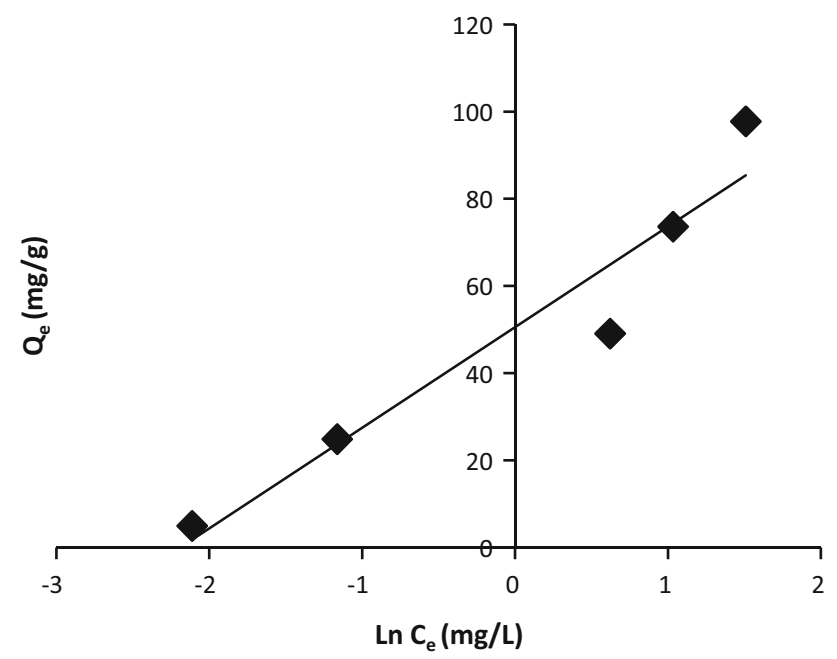

Fig. 17 Temkin isotherm model for sorption of $\mathrm{Cu}^{2+}$ onto nZVMn

(Fig. 16b; Table 4) from this research range from $2.03 \times 10^{-2}$ to $2.93 \times 10^{-1}$ which is less than unity indicating a favourable adsorption.

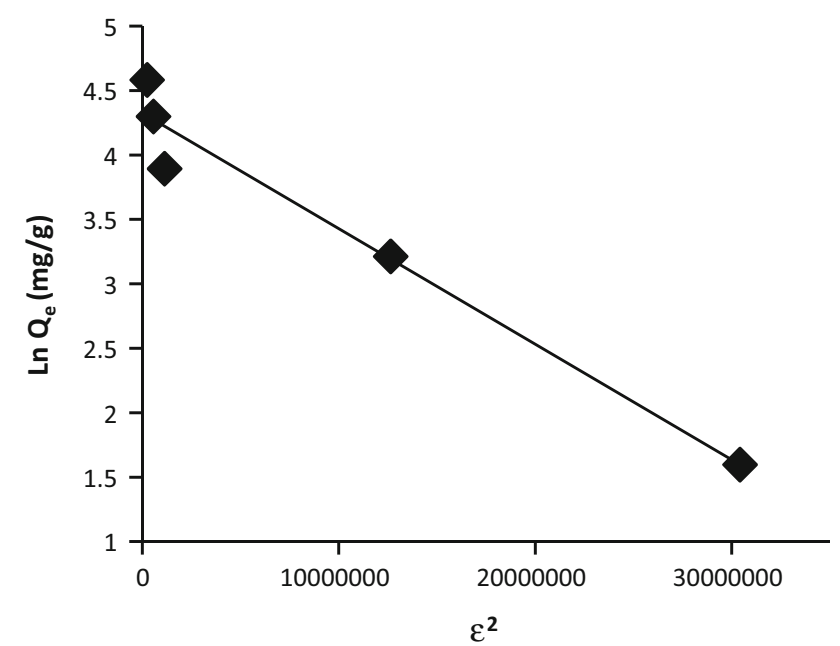

Fig. 18 DKR isotherm model for sorption of $\mathrm{Cu}^{2+}$ onto nZVMn

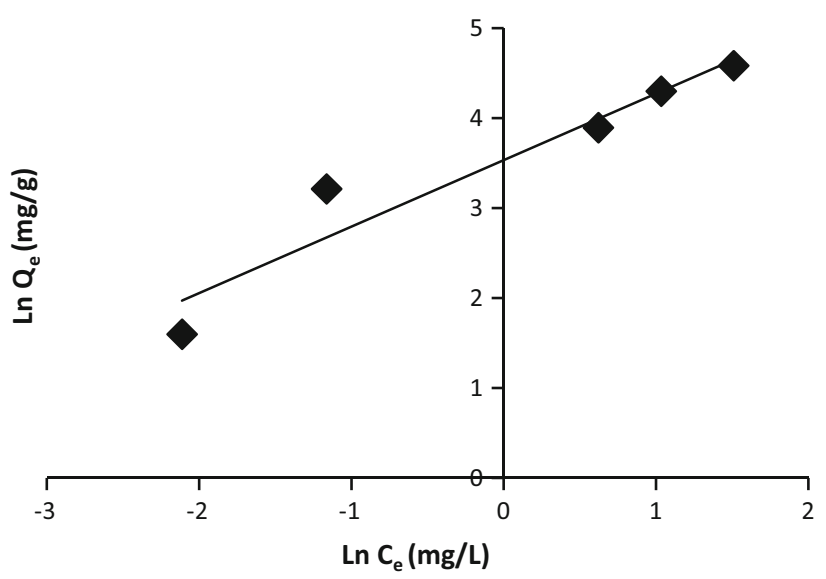

Fig. 19 Halsey isotherm model for sorption of $\mathrm{Cu}^{2+}$ onto nZVMn

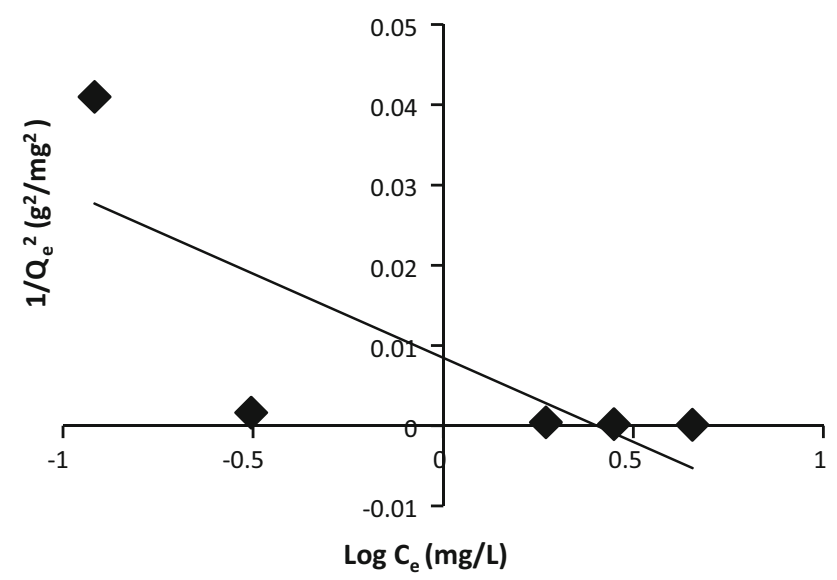

Fig. 20 Harkin-Jura isotherm model for sorption of $\mathrm{Cu}^{2+}$ onto nZVMn 


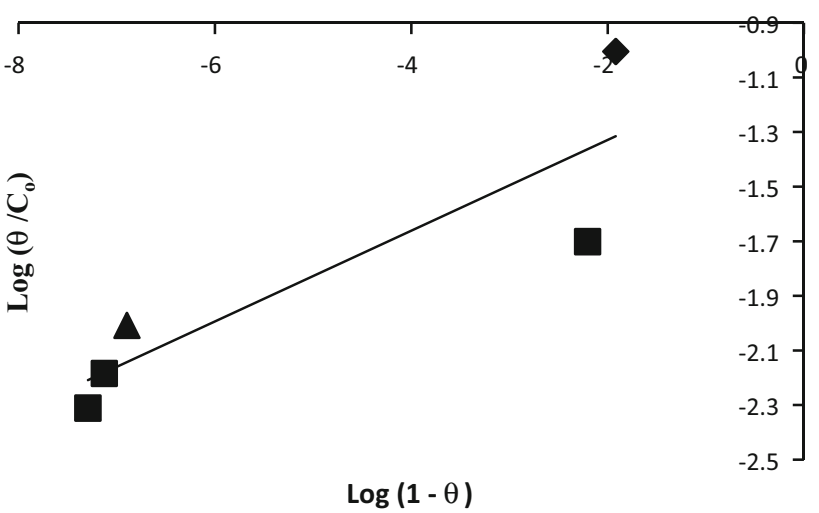

Fig. 21 Flory-Huggins isotherm model for sorption of onto nZVMn

Table 4 Langmuir, Freundlich, Temkin, DKR, Halsey, Harkin-Jura and Flory-Huggins isotherm models parameters and correlation coefficients for adsorption of copper ions onto nZVMn particles

\begin{tabular}{|c|c|c|}
\hline Isotherm models & Parameters & $\mathrm{Cu}^{2+}$ \\
\hline \multirow[t]{4}{*}{ Freundlich } & $k_{\mathrm{f}}$ & 90.824 \\
\hline & $1 / n_{\mathrm{F}}$ & 0.739 \\
\hline & $n_{\mathrm{F}}$ & 1.352 \\
\hline & $R^{2}$ & 0.921 \\
\hline \multirow[t]{4}{*}{ Langmuir } & $Q_{\max }\left(\mathrm{mg} \mathrm{g}^{-1}\right)$ & 181.818 \\
\hline & $K_{\mathrm{L}}\left(\mathrm{L} \mathrm{mg}^{-1}\right)$ & 0.241 \\
\hline & $R_{\mathrm{L}}\left(\times 10^{-1}\right)$ & $0.203-2.93$ \\
\hline & $R^{2}$ & 0.911 \\
\hline \multirow[t]{4}{*}{ Temkin } & $b_{T}\left(\mathrm{~J} \mathrm{~mol}^{-1}\right)$ & 107.352 \\
\hline & $\beta\left(\mathrm{Lg}^{-1}\right)$ & 23.079 \\
\hline & $A_{T}\left(\mathrm{Lg}^{-1}\right)$ & 8.934 \\
\hline & $R^{2}$ & 0.925 \\
\hline \multirow[t]{4}{*}{ DRK } & $Q_{\mathrm{d}}$ & 75.467 \\
\hline & $A_{\mathrm{DRK}}$ & $9 \times 10^{-8}$ \\
\hline & $E(\mathrm{KJ} / \mathrm{mol})$ & 2.357 \\
\hline & $R^{2}$ & 0.967 \\
\hline \multirow[t]{4}{*}{ Halsey } & $1 / n$ & -0.739 \\
\hline & $n_{\mathrm{H}}$ & -1.352 \\
\hline & $K_{\mathrm{H}}$ & $8.416 \times 10^{-3}$ \\
\hline & $R^{2}$ & 0.921 \\
\hline \multirow[t]{4}{*}{ Harkin-Jura } & $1 / A_{\mathrm{H}-\mathrm{J}}$ & 0.021 \\
\hline & $A_{\mathrm{H}-\mathrm{J}}$ & 47.619 \\
\hline & $B$ & 0.405 \\
\hline & $R^{2}$ & 0.605 \\
\hline \multirow[t]{3}{*}{ Flory-Huggins } & $n_{\mathrm{FH}}$ & 0.166 \\
\hline & $K_{\mathrm{FH}}$ & 0.101 \\
\hline & $R^{2}$ & 0.779 \\
\hline
\end{tabular}

The copper adsorption capacity on nZVMn is $181.818 \mathrm{mg} \mathrm{g}^{-1}$ (Table 5). This is much higher compared to other nano-adsorbents reported in the literature such as stated in Table 5. This high adsorption capacity is due to high BET surface area. Based on the comparison between zerovalent manganese nanoparticle (nZVMn) and other nano-adsorbents previously used in adsorption of $\mathrm{Cu}^{2+}$ (Table 5), nZVMn can be enlisted among novel and promising adsorbents (Hao et al. 2010).

Figure 17 depicts the linear plot of Temkin isotherm model for adsorption of $\mathrm{Cu}^{2+}$ onto nZVMn. The Temkin isotherm constant, $b_{T}$, related to the heat of adsorption and the Temkin isotherm equilibrium binding constant $\left(A_{T}\right)$ $\left(\mathrm{L} \mathrm{g}^{-1}\right)$ were determined from the slope and intercept as 107.352 $\mathrm{J} \mathrm{mol}^{-1}$ and $8.934 \mathrm{~L} \mathrm{~g}^{-1}$, respectively. Observation from Table 4 shows that the $R^{2}$ values of Temkin and Langmuir are close.

The adsorption data also fitted well into DKR model based on $R^{2}$ value (Fig. 18, Table 4). Since the magnitude of $\mathrm{E}$ (free energy of transfer of one solute from infinity to the surface of $\mathrm{nZVMn}$ ) is less than $8 \mathrm{~kJ} \mathrm{~mol}^{-1}$, the adsorption mechanism was physisorption which further supported Freundlich Isotherm. This finding is supported by the report of Song et al. (2014) and Lisha et al. (2010).

The adsorption data also fitted well to Halsey isotherm model (Fig. 19) with $R^{2}=0.921$ (Table 4) to further support the prevalence of multilayer adsorption process. Only Harkin-Jura (Fig. 20) and Flory-Huggins (Fig. 21) poorly described the adsorption process and this was confirmed with their low $R^{2}$ values in Table 4.

\section{Thermodynamic studies}

Temperature is another important parameter in the adsorption studies because some important thermodynamic parameters like enthalpy change $(\Delta H)$, entropy change $(\Delta S)$ and Gibbs free energy change $(\Delta G)$ could be determined. From the enthalpy change, endothermic and exothermic nature of the system could be determined; the degree of disorderliness of the system would be determined from the change in entropy while Gibbs free energy change gives information about the feasibility and spontaneity of the system. Figure 22 below shows the effect of temperature on the adsorption of $\mathrm{Cu}^{2+}$ onto nZVMn. Five different temperatures $(298,308,318,328$ and $338 \mathrm{~K})$ were investigated in this research. It can be inferred that increase in temperature led to increase in the removal efficiency of $\mathrm{Cu}^{2+}$ which may be due to increase in number of active sites and the decrease in the thickness of the boundary layer surrounding the adsorbent with temperature, so that the mass transfer resistance of adsorbate in the boundary layer decreases (Dogan et al. 2009). Moreover, increasing temperature resulted in an increase in the rate of approach to equilibrium. The positive value of enthalpy change indicated that the adsorption process of $\mathrm{Cu}$ (II) ions onto nZVMn was endothermic. This was further confirmed by the Van't Hoff plot. 
Table 5 Comparison of the adsorption capacities of nano-adsorbent used for $\mathrm{Cu}^{2+}$ removal

\begin{tabular}{|c|c|c|c|}
\hline $\begin{array}{l}\mathrm{S} / \\
\mathrm{N}\end{array}$ & Adsorbents & $\begin{array}{l}\text { Adsorption capacity }\left(Q_{\max }\right)(\mathrm{mg} / \\
\text { g) }\end{array}$ & References \\
\hline 1 & Magnetite & 126.9 & Febrianto et al. (2009) \\
\hline 2 & Kaolin Fe/Ni nanoparticles & 107.8 & Xiao et al. (2011) \\
\hline 3 & S-doped $\mathrm{TiO}_{2}$ & 96.3 & Li et al. (2011) \\
\hline 4 & Magnetic nanoparticles coated by chitosan carrying of [1]-ketoglutaric acid & 96.15 & Zhou et al. (2009) \\
\hline 5 & Pectin-iron oxide & 48.99 & Gong et al. (2012) \\
\hline 6 & Carboxymethyl- $\beta$-cyclodextrin-conjugated magnetics nanoparticle & 47.29 & Badruddoza et al. (2011) \\
\hline 7 & $\mathrm{Fe}_{3} \mathrm{O}_{4}$ magnetic nanoparticles coated with humic acid & 46.3 & Liu et al. (2013) \\
\hline 8 & Magnetic gamma- $\mathrm{Fe}_{2} \mathrm{O}_{3}$ nanoparticles coated with poly-L-cysteine & 42.9 & White et al. (2009) \\
\hline 9 & Magnetic nano-adsorbent modified by gum arabic & 38.5 & Banerjee and Chen (2007) \\
\hline 10 & Hydroxyapatite nanoparticles & 36.9 & Wang et al. (2009) \\
\hline 11 & Maghemite nanoparticle & 27.7 & Hu et al. (2006) \\
\hline 12 & Amino-functionalized magnetic nanosorbent & 25.77 & Hao et al. (2010) \\
\hline 13 & Chitosan-bound $\mathrm{Fe}_{3} \mathrm{O}_{4}$ magnetic nanoparticles & 21.5 & Chang and Chen (2005) \\
\hline 14 & Manganese nanoparticles & 181.82 & This present study \\
\hline
\end{tabular}

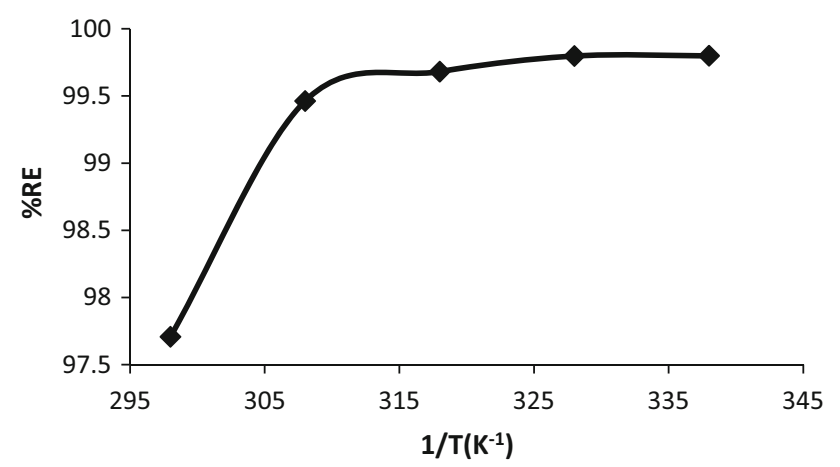

Fig. 22 Effect of temperature on $\mathrm{Cu}^{2+}$ adsorbed onto nZVMn. Experimental conditions: optimum $\mathrm{Cu}^{2+}$ concentration $=100 \mathrm{ppm}$; volume of $\mathrm{Cu}^{2+}$ solution $=50 \mathrm{~mL} ;$ nZVMn dose $=100 \mathrm{mg}$; $\mathrm{pH}=5$, contact time $=60 \mathrm{~min}$, and temperature $=25 \pm 2{ }^{\circ} \mathrm{C}$

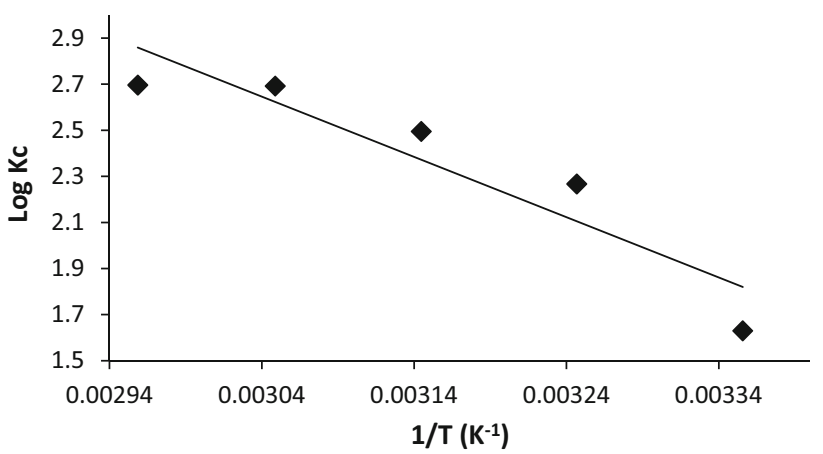

Fig. 23 Van't Hoff plot on sorption of $\mathrm{Cu}^{2+}$ onto nZVMn nanoadsorbent

The Van't Hoff plot of $\log K_{\mathrm{c}}$ versus $1 / T$ in Fig. 23 gave a straight line and the thermodynamic parameters, standard enthalpy change $\Delta H^{\circ}\left(\mathrm{kJ} \mathrm{mol}^{-1}\right)$ and standard entropy
Table 6 Thermodynamic parameters for adsorption of $\mathrm{Cu}^{2+}$ onto nZVMn

\begin{tabular}{llllll}
\hline$T\left({ }^{\circ} \mathrm{C}\right)$ & $T(\mathrm{~K})$ & $\begin{array}{l}\Delta G \\
\left(\mathrm{KJ} \mathrm{mol}^{-1}\right)\end{array}$ & $\begin{array}{l}\Delta H \\
\left(\mathrm{KJ} \mathrm{mol}^{-1}\right)\end{array}$ & $\begin{array}{l}\Delta S \\
\left(\mathrm{~J} \mathrm{~mol}^{-1} \mathrm{~K}^{-1}\right)\end{array}$ & $\mathrm{Ka}$ \\
\hline 25 & 298 & -9.29891 & +50.27848 & +203.5724 & 42.63002 \\
35 & 308 & -13.3685 & & & 184.8736 \\
45 & 318 & -15.1904 & & & 312.4796 \\
55 & 328 & -16.9041 & & & 491.6108 \\
65 & 338 & -17.4473 & & & 496.5124 \\
\hline
\end{tabular}

change $\Delta S^{\circ}\left(\mathrm{J} \mathrm{mol}^{-1} \mathrm{~K}^{-1}\right)$ were determined from the slope and intercept, respectively. The standard Gibbs free energy $\Delta G^{\circ}\left(\mathrm{kJ} \mathrm{mol}^{-1}\right)$, was calculated using the Eq. 30. Table 6 below shows the values of thermodynamic parameters of the adsorption of $\mathrm{Cu}^{2+}$ onto nZVMn. It can, therefore, be ascertained from the positive value of $\Delta H(\Delta H=+50.27848$

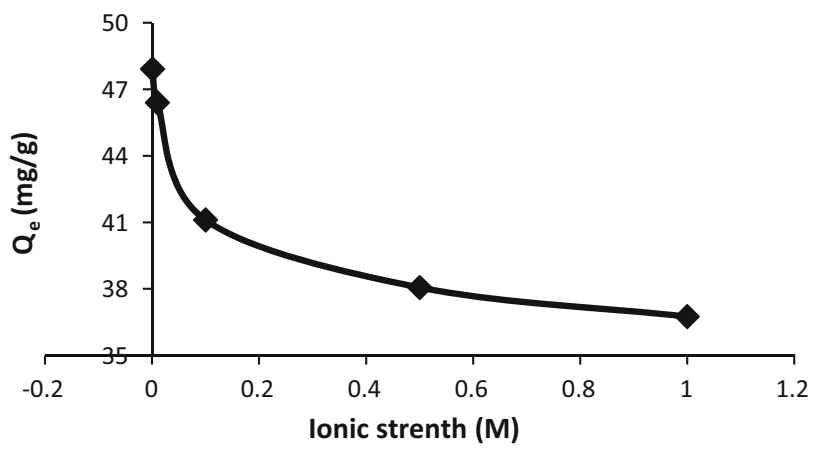

Fig. 24 Ionic strength on $\mathrm{Cu}^{2+}$ adsorbed onto nZVMn. Experimental conditions: $\mathrm{Cu}^{2+}$ concentration $=100 \mathrm{ppm}$; volume of $\mathrm{Cu}^{2+}$ solution $=50 \mathrm{~mL} ; \mathrm{nZVMn}$ dose $=100 \mathrm{mg} ; \mathrm{pH}=5$, contact time $=60$ min, stirring speed $=200 \mathrm{rpm}$ and temperature $=25 \pm 2{ }^{\circ} \mathrm{C}$ 
$\mathrm{kJ} \mathrm{mol}^{-1}$ ) that the reaction is endothermic (Table 6). The standard entropy change $\Delta S^{\circ}\left(203.5724 \mathrm{~J} \mathrm{~mol}^{-1} \mathrm{~K}^{-1}\right)$ indicated the degree of randomness at the solid-liquid interface during the adsorption of $\mathrm{Cu}^{2+}$ onto $\mathrm{nZVMn}$ and the negative values of the standard Gibbs free energy $\Delta G^{\circ}$ indicated the feasibility and spontaneity of the adsorption process. This finding is in support with the report of other researchers (Hao et al. 2010; Lisha et al. 2010).

\section{Effect of salinity on adsorption of $\mathrm{Cu}(\mathrm{II})$}

Figure 24 shows the influence of salinity (ionic strength) on $\mathrm{Cu}^{2+}$ adsorbed onto nZVMn at optimum conditions. This investigation was carried out using $\mathrm{NaCl}$ solution of different ionic strength from 0.001 to $1.0 \mathrm{M}$. Increase in ionic strength led to decrease in the percentage removal efficiency from 95.82 to $73.49 \%$ and the quantity adsorbed also decreased from 47.91 to $36.75 \mathrm{mg} / \mathrm{g}$. This decrease in the amount of copper uptake was due to increase in the electrostatic attraction arising from compressed electrical diffuse double layer. Also, increase in the number of adsorbate species led to electrostatic competition between copper ions and sodium ions on the available adsorption sites (Liu et al. 2013; Gong et al. 2012; Xiao et al. 2011; Hao et al. 2010; Dogan et al. 2009; Larous et al. 2005).

\section{Conclusion}

This study has successfully investigated the synthesis, characterization and application of novel zerovalent manganese nanoparticle for adsorption of $\mathrm{Cu}^{2+}$. Results from this study suggested that adsorption of $\mathrm{Cu}^{2+}$ depended on all operational factors such as effect of initial concentration, contact time, $\mathrm{pH}$, adsorbent dose, agitation speed, and temperature investigated. Pseudo second order well described the kinetics of the process and the mechanism was governed by pore diffusion which was validated by sum of square error (SSE), Chi-square $\left(\chi^{2}\right)$ and normalized standard variation $(\Delta q) \%$ statistical models The equilibrium data fitted well to Langmuir, Freundlich, Temkin, DKR and Halsey isotherm models. However, the value of the mean energy evaluated from DKR model indicated that electrostatic force played a role in adsorption process. The thermodynamic studies showed that the adsorption process is feasible, endothermic and spontaneous in nature. Outcome of this study enlisted nanoscale zerovalent manganese (nZVMn) as a potential and novel nano-adsorbent for the adsorption of heavy metal ions and can be recommended for industrial treatment of effluent.

Acknowledgments Dada, Adewumi Oluwasogo appreciates the Management of Landmark University for giving me the opportunity to undertake and finish my Ph.D. programme in University of Ilorin. The assistance rendered by Ogunlaja Adeniyi in Rhodes University, South Africa for the TEM, SEM and EDX analyses is highly appreciated.

Open Access This article is distributed under the terms of the Creative Commons Attribution 4.0 International License (http:// creativecommons.org/licenses/by/4.0/), which permits unrestricted use, distribution, and reproduction in any medium, provided you give appropriate credit to the original author(s) and the source, provide a link to the Creative Commons license, and indicate if changes were made.

\section{References}

Adekola FA, Abdus-Salam N, Adegoke HI, Adesola MA, Adekeye JID (2012) Removal of $\mathrm{Pb}$ (II) from aqueous solution by natural and synthetic calcites. Bull Chem Soc Ethiop 26(2):195-210

Ahmad MA, Ahmad N, Bello OS (2014a) Adsorptive removal of malachite green dye using durian seed-based activated carbon. Water Air Soil Pollut 225:2057. doi:10.1007/s11270-014-2057-z

Ahmad MA, Ahmad N, Bello OS (2014) Modified durian seed as adsorbent for the removal of methyl red dye from aqueous solutions. Appl Water Sci. doi:10.1007/s13201-014-0208-4

Ahmad MA, Puad NAA, Bello OS (2014c) Kinetic, equilibrium and thermodynamic studies of synthetic dye removal using pomegranate peel activated carbon prepared by microwave-induced KOH activation. Water Res Ind. doi:10.1016/j.wri.2014.06.002

Ayanda OS, Fatoki SO, Adekola FA, Ximba BJ (2013) Kinetics and equilibrium models of the adsorption of tributyltin to $\mathrm{nZnO}$, activated carbon and $\mathrm{nZnO} /$ activated carbon composite in artificial seawater. Mar Pollut Bull. doi:10.1016/j.marpolbul. 2013.04.001

Badruddoza AZM, Tay ASH, Tan PY, Hidajat K, Uddin MS (2011) Carboxymethyl- $\beta$-cyclodextrin conjugated magnetic nanoparticles as nano-adsorbents for removal of copper ions: synthesis and adsorption studies. J Hazard Mater 185:1177-1186

Banerjee SS, Chen DH (2007) Fast removal of copper ions by gum arabic modified magnetic nano-adsorbent. J Hazard Mater 147:792-799

Basar CA (2006) Applicability of the various adsorption models of three dyes adsorption onto Activated Carbon Prepared from Waste Apricot. J Hazard Mater B135:232-241

Bello OS, Ahmad MA, Semire B (2014) Scavenging malachite green dye from aqueous solutions using pomelo (Citrus grandis) peels: kinetic, equilibrium and thermodynamic studies. Desalin Water Treat. doi:10.1080/19443994.2014.940387

Bhatt RR, Shah BA (2013) Adsorption studies of heavy metal ions by salicylic acid-formaldehyde-catechol terpolymeric resin: isotherm, kinetic and thermodynamics. Arabian J Chem. doi:10. 1016/j.arabjc.2013.03.012(2013)

Bonnie RS, Marc S, Daniel K, Peter A, Tar-Ching SB et al (2007) Copper and human health: biochemistry, genetics, and strategies for modeling dose-response relationships. J Toxicol Environ Health Part B 10:157-222

Boparai HK, Meera J, Dennis MO (2010) Kinetics and thermodynamics of cadmium ion removal by adsorption onto nano zerovalent iron particles. J Harzard Mater. doi:10.1016/j. jhazmat.2010.11.029

Brewer GJ (2010) Copper toxicity in the general population. Clin Neurophysiol 121(4):459-460. doi:10.1016/j.clinph.209.12. 015PMID20071223

Cai X, Gao Y, Sun Q, Chen Z, Megharaj M, Naidu R (2014) Removal of co-contaminants $\mathrm{Cu}(\mathrm{II})$ and nitrate from aqueous solution using kaolin-Fe/Ni nanoparticles. Chem Eng J 244:19-26

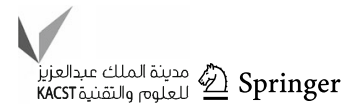


Chang YC, Chen DH (2005) Preparation and adsorption properties of monodisperse chitosan-bound $\mathrm{Fe}_{3} \mathrm{O}_{4}$ magnetic nanoparticles for removal of $\mathrm{Cu}(\mathrm{II})$ ions. J Colloid Interface Sci 283:446-451

Chen Z-X, Jin X-Y, Chen Z, Megharaj M, Naidu R (2011) Removal of methyl orange from aqueous solution using bentonitesupported nanoscale zero-valent iron. J Colloid Interface Sci 363:601-607

Chingombe P, Saha B, Wakeman RJ (2006) Adsorption of atrazine on conventional and surface modified activated carbons. J Colloid Interface Sci 302:408-416

Cho D-W, Jeon B-H, Chon C-M, Kim Y, Schwartz FW, Lee E-S, Song H (2012) A novel chitosan/clay/magnetite composite for adsorption of $\mathrm{Cu}(\mathrm{II})$ and $\mathrm{As}(\mathrm{V})$. Chem Engg J 200-202:654-662

Dada AO, Adekola FA, Odebunmi EO (2014) Investigation of the synthesis and characterization of manganese nanoparticles and its ash rice husk supported nanocomposite. In: Book of proceedings of 1st African International Conference/Workshop on applications of nanotechnology to energy, health and environment-March 23rd-29th

Dada AO, Adekola FA, Odebunmi EO (2014) Kinetics, isotherms and thermodynamics studies of adsorption of $\mathrm{Cu}^{2+}$ onto novel zerovalent iron nanoparticles. Covenant $J$ Phys Life Sci 2(1):24-53

Doğan M, Türkyilmaz A, Alkan M, Demirbaş Ö (2009) Adsorption of copper (II) ions onto sepiolite and electrokinetic properties. Desalination 238:257-270

Edison TJI, Sethuraman MG (2013) Biogenic robust synthesis of silver nanoparticles using Punica granatum peel and its application as a green catalyst for the reduction of an anthropogenic pollutant 4-nitrophenol. Spectrochim Acta Part A Mol Biomol Spectrosc 104:262-264

Febrianto J, Kosasih AN, Sunarso J, Ju Y-H, Indraswatib N, Ismadji S (2009) Equilibrium and kinetic studies in adsorption of heavy metals using biosorbent: a summary of recent studies. J Hazard Mater 162:616-645

Foo KY, Hameed BH (2010) Review: insights into the modeling of adsorption isotherm systems. Chem Engg J 156:2-10

Gong J, Chen L, Zeng G, Long F, Deng J, Niu Q, He X (2012) Shellac-coated iron oxide nanoparticles for removal of cadmium (II) ions from aqueous solution. J Environ Sci. 24(7):1165-1173

Gonga J-L, Wanga X-Y, Zeng G-M, Chen L, Denga J-H, Zhang X-R, Niu Q-Y (2012) Copper (II) removal by pectin- iron oxide magnetic nanocomposite adsorbent. Chem Engg J 185-186:100-107

Hameed BH, Mahmoud DK, Ahmad AL (2008) Equilibrium modeling and kinetic studies on the adsorption of basic dye by a lowcost adsorbent: coconut (Cocos nucifera) bunch waste. J Hazard Mater 158:65-72

Hao Y-M, Chen M, Hu Z-B (2010) Effective removal of Cu(II) ions from aqueous solution by amino-functionalized magnetic nanoparticles. J Hazard Mater 184:392-399

Harkins WD, Jura GJ (1944) The decrease of free surface energy as a basis for the development of equations for adsorption isotherms; and the existence of two condensed phases in films on solids. J Chem Phys 12:112-113

Ho YS (2004) Pseudo-isotherms using a second order kinetic expression constant. Adsorption 10:151-158

Ho YS, McKay G (2003) Adsorption of dyes and copper ions onto bio-sorbents. Process Biochem 38:1047-1061

Hu J, Chen GH, Lo IMC (2006) Selective removal of heavy metals from industrial wastewater using maghemite nanoparticle: Performance and mechanisms, J Environ Eng ASCE 132:709-715

Huang S-H, Chen D-H (2009) Rapid removal of heavy metal cations and anions from aqueous solutions by an amino-functionalized magnetic nano-adsorbent. J Hazard Mater 163:174-179
Igwe JC, Abia AA (2006) A bioseparation process for removing heavy metals from waste water using biosorbents. African J Biotechnol 5(12):1167-1179

Igwe JC, Abia AA, Ibeh CA (2005) Adsorption kinetics and intraparticulate diffusivities of $\mathrm{Hg}$, As and $\mathrm{Pb}$ ions on unmodified and thiolated coconut fiber. Int J Environ Sci Technol 5:83-92

Jaafar MZ, Nasir AM, Hamid MF (2013) Point of zero charge for sandstone and carbonate rocks bt streaming potential. Int J Pet Geosci Eng 1(2):82-90

Jain PL, Huang X, El Sayed LH, El Sayed MA (2007) Review of some interesting surface plasmon resonance-enhanced properties of noble metal Nanoparticles and their applications to biosystems. Plasmonics 2:107-118

Kara A, Demirbel E (2012) Physicochemical parameters of $\mathrm{Cu}(\mathrm{II})$ ions adsorption from aqueous Solution by magnetic-poly(divinylbenzene- $N$-vinylimidazole) microbeads. Sep Sci Technol 47(5):709-722

Karabellia D, Ünal S, Shahwan T, Erŏglu AE (2011) Preparation and characterization of alumina-supported iron nanoparticles and its application for the removal of aqueous $\mathrm{Cu}^{2+}$ ions. Chem Eng J 168:979-984

Kumar V, Yadav KS (2011) Synthesis of stable, polyshaped silver, and gold nanoparticles using leaf extract of Lonicera japonica $\mathrm{L}$. Int J Green Nanotechnol 3:281-291

Kumar PS, Vincent C, Kirthika K, Kumar KS (2010) Kinetics and equilibrium studies of $\mathrm{Pb}^{2+}$ ion removal from aqueous solutions by use of nano-silversolcoated activated carbon. Braz J Chem Eng 27:339-346

Larous S, Meniai AH, Lehocine BM (2005) Experimental study of the removal of copper from aqueous solution by adsorption using Sawdust. Desalination 185:483-490

Li E, Zeng X, Fan Y (2009) Removal of chromium ion (III) from aqueous solution by manganese oxide and microemulsion modified diatomite. Desalination 238:158-165

Li D, Wang X, Wan D, Duan S, Liu C, Zhang K, Fang B (2011) Adsorption of $\mathrm{Cu}^{2+}$ cations from aqueous solution by $\mathrm{S}$-doped $\mathrm{TiO}_{2}$. Sep Sci Technol 46:2539-2548

Lisha KP, Shihabudheen M, Pradeep MT (2010) Manganese dioxide nanowhiskers: a potential adsorbent for the removal of $\mathrm{Hg}(\mathrm{II})$ from water. Chem Eng J 160:432-439

Liu JF, Zhao ZS, Jiang GB (2008) Coating $\mathrm{Fe}_{3} \mathrm{O}_{4}$ magnetic nanoparticles with humic acid for high efficient removal of heavy metals in water. Environ Sci Technol 42:6949-6954

Liu W, Wang T, Borthwick AGL, Wang Y, Yin X, Li X, Ni J (2013) Adsorption of $\mathrm{Pb}^{2+}, \mathrm{Cd}^{2+}, \mathrm{Cu}^{2+}$ and $\mathrm{Cr}^{3+}$ onto titanate nanotubes: competition and effect of inorganic ions. Sci Total Environ 456-457:171-180

Prasad TNVKV, Elumalai EK (2011) Biofabrication of Ag nanoparticles using moringa oleifera leaf extract and their antimicrobial activity. Asian Pac J Trop Biomed. 1(6):439-442. doi:10.1016/ S2221-1691(11)60096-8

Prathna TC, Mathew L, Chandrasekaran N, Raichur AM, Mukherjee A (2012) Biomimetic synthesis of nanoparticles: science, technology and applicability, School of BioSciences and Technology, VIT University Department of Materials Engg., Indian Institute of Science, India, pp 1-20

Ren YM, Wei XZ, Zhang ML (2008) Adsorption character for removal $\mathrm{Cu}$ (II) by magnetic $\mathrm{Cu}(\mathrm{II})$ ion imprinted composite adsorbent. J Hazard Mater 158:14-22

Roosta M, Ghaedi M, Daneshfar A, Sahraei R, Asghari A (2014) Optimization of the ultrasonic assisted removal of methylene blue by gold nanoparticles loaded on activated carbon using experimental design methodology. Ultrason Sonochemistry 21(1):242-252

Sikdera T, Mihara Y, Islam S, Saito T, Tanaka S, Kurasaki M (2014) Preparation and characterization of chitosan-caboxymethyl- $\beta$ - 
cyclodextrin entrapped nanozerovalent iron composite for $\mathrm{Cu}(\mathrm{II})$ and $\mathrm{Cr}(\mathrm{IV})$ removal from wastewater. Chem Engg J 236:378-387

Sinha A, SinghVN Mehta BR, Khare SK (2011) Synthesis and characterization of monodispersed orthorhombic manganese oxide nanoparticles produced by Bacillus sp. cells simultaneous to its bioremediation. J Hazard Mater 192:620-627

Song C, Wu S, Cheng M, Tao P, Shao M, Gao G (2014) Adsorption studies of coconut shell carbons prepared by $\mathrm{KOH}$ activation for removal of lead (II) from aqueous solutions. Sustainability 6:86-98. doi:10.3390/su6010086

Srivastava VC, Mall ID, Mishra IM (2005) Characterization of mesoporous rice husk ash (RHA) and adsorption kinetics of metal ions from aqueous solution onto RHA. J Hazard Mater. doi:10.1016/j.jhazmat.11.052

Temkin MI, Pyzhev V (1940) Kinetic of ammonia synthesis on promoted iron catalysts. Acta Physiochim URSS 12:327-356

Waghmare SS, Deshmukh AM, Kulkarni SW, Oswaldo LA (2011) Biosynthesis and characterization of manganese and zinc nanoparticles. Univers J Environ Res Technol 1:64-69

Wang YJ, Chen JH, Cui YX, Wang SQ, Zhou DM (2009) Effects of low-molecular weight organic acids on $\mathrm{Cu}(\mathrm{II})$ adsorption onto hydroxyapatite nanoparticles. J Hazard Mater 162:1135-1140

Weber WJ, Morris JC (1963) Kinetics of adsorption on carbon from solution. J Sanit Eng Div ASCE 89:31-59 (Mater 161:848-853)
White BR, Stackhouse BT, Holcombe JA (2009) Magnetic gamma$\mathrm{Fe} 2 \mathrm{O} 3$ nanoparticles coated with poly-lcysteine for chelation of $\mathrm{As}(\mathrm{III}), \mathrm{Cu}(\mathrm{II}), \mathrm{Cd}(\mathrm{II}), \mathrm{Ni}(\mathrm{II}), \mathrm{Pb}(\mathrm{II})$ and $\mathrm{Zn}$ (II). J. Hazard. Mater. 161:848-853

Wojtysiak W, Kudelski A (2012) Influence of oxygen on the process of formation of silver nanoparticles during citrate/borohydride synthesis of silver sols. Colloids Surf A Physicochem Engl Asp 410:45-51

Wu FC, Tseng RI, Jung RS (2001) Kinetic modeling of liquid-phase adsorption of reactive dyes and metal ions on chitosan. Water Res 35:613-618

Xi Y, Megharaj M, Naiduv R (2011) Dispersion of zerovalent iron nanoparticles onto bentonites and use of these catalysts for orange II decolourisation. Appl Clay Sci 53:716-722

Xiao S, Ma H, Shen M, Wang S, Huang Q, Shi X (2011) Excellent copper (II) removal using zero-valent iron nanoparticle-immobilized hybrid electrospun polymer nanofibrous mats. Colloids Surf A Physicochem Engl Asp 381:48-54

Xu H, Liu Y, Tay J (2006) Effect of pH on nickel bioadsorption by aerobic granular sludge', Bioresour Technol 97(3):359-363

Zhou YT, Nie HL, Branford-White C, He ZY, Zhu LM (2009) Removal of $\mathrm{Cu}^{2+}$ from aqueous solution by chitosan-coated magnetic nanoparticles modified with $\alpha$-ketoglutaric acid. J Colloid Interface Sci 330:29-37 